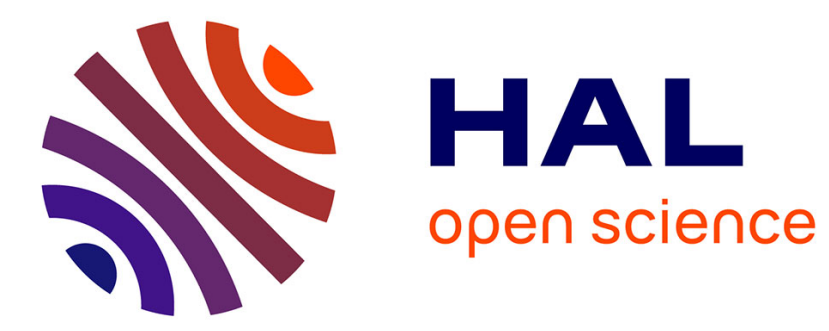

\title{
Operational Implementation of the 1D13D-Var Assimilation Method of Radar Reflectivity Data in the AROME Model
}

Eric Wattrelot, Olivier Caumont, Jean-Francois Mahfouf

\section{- To cite this version:}

Eric Wattrelot, Olivier Caumont, Jean-Francois Mahfouf. Operational Implementation of the 1D13DVar Assimilation Method of Radar Reflectivity Data in the AROME Model. Monthly Weather Review, 2013, 142, pp.1852-1871. 10.1175/MWR-D-13-00230.1 . meteo-01001390

\section{HAL Id: meteo-01001390}

https://hal-meteofrance.archives-ouvertes.fr/meteo-01001390

Submitted on 4 Jun 2014

HAL is a multi-disciplinary open access archive for the deposit and dissemination of scientific research documents, whether they are published or not. The documents may come from teaching and research institutions in France or abroad, or from public or private research centers.
L'archive ouverte pluridisciplinaire HAL, est destinée au dépôt et à la diffusion de documents scientifiques de niveau recherche, publiés ou non, émanant des établissements d'enseignement et de recherche français ou étrangers, des laboratoires publics ou privés. 


\title{
¿Operational Implementation of the 1D+3D-Var Assimilation Method of Radar Reflectivity Data in the AROME Model
}

\author{
Eric Wattrelot, Olivier Caumont, And JeAn-François MaHFouf \\ Centre National de Recherche Météorologique, Toulouse, France
}

(Manuscript received 18 July 2013, in final form 9 November 2013)

\begin{abstract}
This paper presents results from radar reflectivity data assimilation experiments with the nonhydrostatic limited-area model Application of Research to Operations at Mesoscale (AROME) in an operational context. A one-dimensional (1D) Bayesian retrieval of relative humidity profiles followed by a three-dimensional variational data assimilation (3D-Var) technique is adopted. Several preprocessing procedures of raw reflectivity data are presented and the use of the nonrainy signal in the assimilation is widely discussed and illustrated. This two-step methodology allows the authors to build up a screening procedure that takes into account the evaluation of the results from the 1D Bayesian retrieval. In particular, the 1D retrieval is checked by comparing a pseudoanalyzed reflectivity to the observed reflectivity. Additionally, a physical consistency between the reflectivity innovations and the 1D relative humidity increments is imposed before assimilating relative humidity pseudo-observations with other observations. This allows the authors to counteract the difficulty of the current 3D-Var system to correct strong differences between model and observed clouds from the crude specification of background-error covariances. Assimilation experiments of radar reflectivity data in a preoperational configuration are first performed over a 1-month period. Positive impacts on short-term precipitation forecast scores are systematically found. The evaluation shows improvements on the analysis and also on objective conventional forecast scores, in particular for the model wind field up to $12 \mathrm{~h}$. A case study for a specific precipitating system demonstrates the capacity of the method for improving significantly short-term forecasts of organized convection.
\end{abstract}

\section{Introduction}

Many numerical weather prediction (NWP) centers have implemented convection-permitting mesoscale models with dedicated data assimilation systems. These models have been developed to improve the prediction of local high-impact weather such as fog, convective storms, wind bursts, etc. At Météo-France, a new highresolution NWP system, Application of Research to Operations at Mesoscale (AROME; Seity et al. 2011) has been running operationally since the fall of 2008 . The AROME code is mostly based on the Action de Recherche Petite Echelle Grande Echelle Integrated Forecast System (ARPEGE-IFS) suite and its derivatives (Courtier et al. 1991). Its dynamical core is derived from the Aire Limitée Adaptation Dynamique

¿ Denotes Open Access content.

Corresponding author address: Eric Wattrelot, Météo-France/ CNRM/GMAP, 42 Av. G. Coriolis, 31057 Toulouse, France.

E-mail: eric.wattrelot@meteo.fr
Développement International (ALADIN-NH) model (Bénard et al. 2010), while its physical parameterizations are taken from the Méso-NH model (Lafore et al. 1998). Ducrocq et al. (2002) have shown that mesoscale analysis can be more important than lateral boundary conditions for successful forecasts of heavy rain patterns and that simulations are particularly sensitive to the initial humidity field. Indeed, small scales cannot just adapt to large scales because of predictability limitations. Highresolution models represent key convective cells with a significant small-scale memory: older convection (such as gust fronts or cold pools) may influence the development of new convective systems. In this context, highfrequency observations can be useful to initialize the AROME model at similar time and space scales. The AROME data assimilation system is derived from ALADIN's three-dimensional variational data assimilation (3D-Var; Fischer et al. 2005), with the same control variables (vorticity, divergence, temperature, surface pressure, and specific humidity). It has an incremental formulation (Courtier et al. 1994) and the background covariances are based on the same multivariate formulation 
as in ALADIN-France (Berre 2000). The AROME 3D-Var uses a specific 3-h assimilation cycle (Brousseau et al. 2011).

Radar data observed by the Application Radar la Météorologie Infrasynoptique (ARAMIS) network (Tabary 2007; Tabary et al. 2007) are well suited to provide high-resolution information about wind and precipitation over a large part of France. Moreover, volumes of radar reflectivities play a key role as they provide information on the three-dimensional structure of precipitating systems useful for the initialization of high-resolution models. However, to extract useful information about the main control variables such as temperature, humidity, or wind from the observed reflectivities is difficult as is also the case at a larger scale from satellite data covering cloud- or precipitationaffected areas (Bauer et al. 2011; Errico et al. 2007). Moreover, with variational techniques, the assimilation of the reflectivity raises a number of issues that question the validity of several fundamental assumptions:

- The background-error matrix allows us to spread spatially the information brought by the observations, but the current covariance structures are mainly isotropic and homogeneous and the cross correlations between humidity and other control variables exist but are rather small (Berre 2000).

- The balance between hydrometeors and temperature, humidity, and the wind field is still badly known and introducing these hydrometeors in the control variable remains a challenge. Michel et al. (2011) points out such problems and suggests the use of an ensemble of shortrange forecasts at high resolution to estimate the background-error covariances (including hydrometeor variables). They propose heterogeneous covariances as a way to separate rainy and nonrainy areas. With fourdimensional variational data assimilation (4D-Var) systems it is possible to achieve implicit error correlations between hydrometeors and other control variables through the linearized model dynamics as shown by Sun and Crook (1997) and more recently Wang et al. (2013b). But, for operational applications at the convective scale, a $4 \mathrm{D}$-Var system is still too expensive. However, 3D-Var systems can achieve indirectly some balance through assimilation cycling.

- It is necessary to code the tangent linear of the observation operator for reflectivity and its adjoint. Since the observation operator for reflectivity is nonlinear (threshold for detection of precipitation), this can entail suboptimalities during the minimization process (Park and Droegemeier 1997). Wang et al. (2013a) have shown that the direct assimilation of reflectivity by using a linearized $Z_{e}-q_{r}$ (reflectivity minus rainwater) equation can provide a strong underestimation of $q_{r}$ (dry bias) when the observation minus model background is large (e.g., if the model is too dry in comparison with observations).

- Nonrainy observations and model equivalents cannot be fully taken into account because of the "no rain" issue (detailed hereafter) that occurs when there is no rain in the first guess but the observation is rainy or the symmetric case. When the model equivalent is nonrainy, rainy profiles cannot be produced since the variational approach requires a small amount of precipitation in the model to have a "nonzero" adjoint sensitivity (Lopez and Bauer 2007; Errico et al. 2007). As a consequence, symmetrically, the use of no-rain observations could lead to strong dry biases.

In that context, the first attempts through case studies to assimilate such reflectivities have shown some benefit for 4D-Var (Sun and Crook 1997) and 3D-Var (Xiao et al. 2007) and more recently by using an indirect assimilation of radar reflectivity with 3D-Var (Wang et al. 2013a) and 4DVar (Wang et al. 2013b; Sun and Wang 2013). In all these studies, cold processes were not taken into account. Indeed, a similar methodology has shown strong limitations when applied to cold microphysics (Wu et al. 2000; Amerault et al. 2008). Other methods to assimilate radar reflectivity have been attempted with more or less success. The ensemble Kalman filter (EnKF) for assimilating radar observations at the convective scale, based mainly on simulated observations, has proved adequate for Doppler winds (Snyder and Zhang 2003). However, the assimilation of radar reflectivity on top of radial velocity only brings small improvements (Tong and Xue 2005; Caya et al. 2005). Therefore, assessments with real radar observations have been limited to specific cases of convective organization (Dowell et al. 2004; Aksoy et al. 2009, 2010).

An alternative to a direct variational approach whose minimization of the cost function could fail is proposed. An original " $1 \mathrm{D}+3 \mathrm{D}$-Var method" to assimilate radar reflectivities was introduced at Météo-France by Caumont et al. (2010), following the same approach proposed by Marécal and Mahfouf $(2000,2002)$ for the assimilation of satellite-derived rain rates. It consists in the retrieval of pseudo-observations of relative humidity from observed reflectivity vertical profiles through a unidimensional Bayesian inversion. This 1D approach has been largely inspired from the methodology used to retrieve precipitation rates and latent heating profiles from satellite observations and from a database of cloud ensemble simulations (Olson et al. 1999; Kummerow et al. 2001). Choosing to assimilate raw reflectivity data requires us to implement an observation operator that 


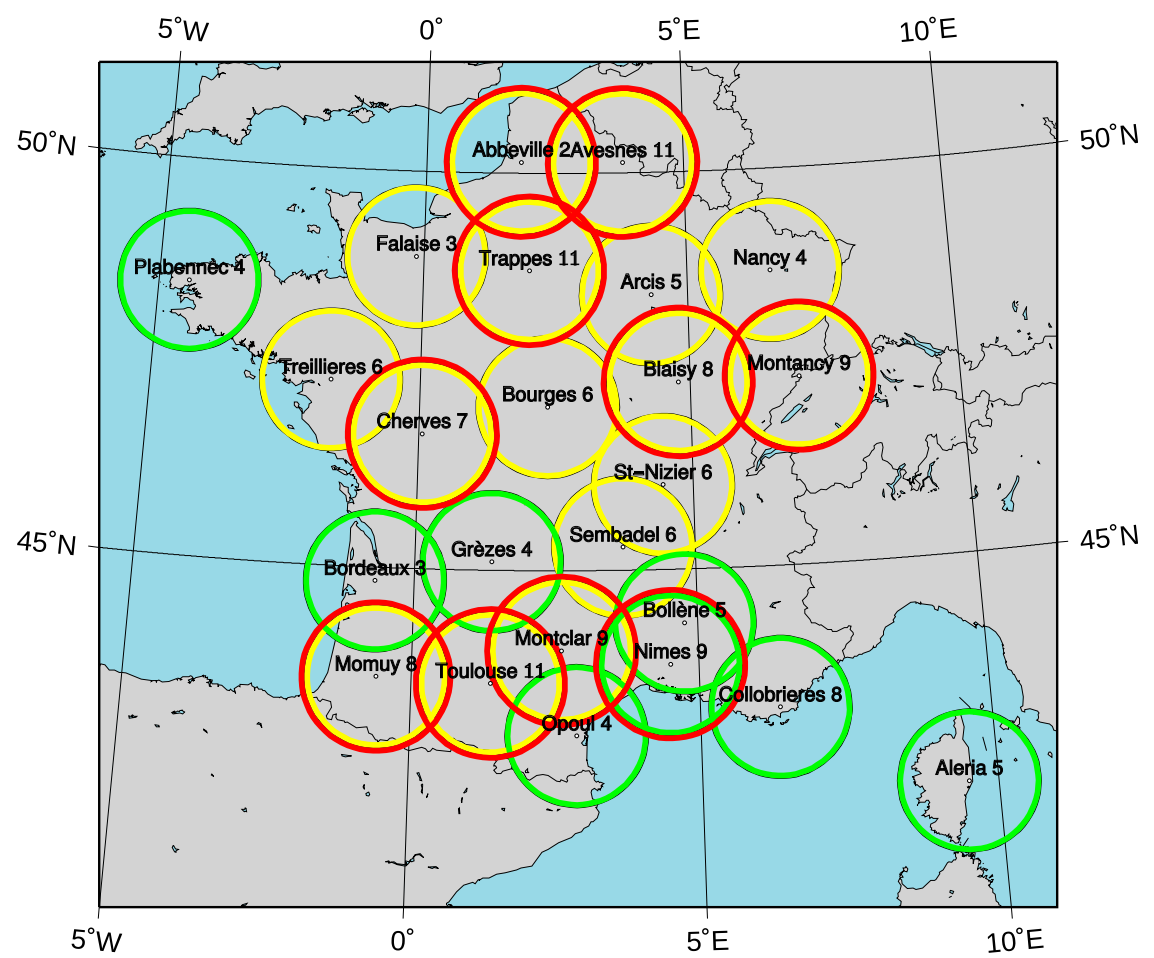

FIG. 1. Map of the French radar network ARAMIS over the AROME domain. Green circles denote S-band radars, yellow circles denote C-band radars, and red circles indicate polarimetric radars. The number of different elevations scanned every $15 \mathrm{~min}$ is provided in the circles.

allows to convert the model control variables (surface pressure, temperature, wind, and moisture) and other prognostic fields as those related to precipitating hydrometeors (rain, snow, and graupel) into a model equivalent radar measurement at the observed location. The difficulties to treat nonlinear moist processes involved in the definition of the observation operator (convection regimes and saturation) are bypassed with the 1D methodology. Then the retrievals are assimilated in the AROME 3D-Var that allows us to benefit from a multivariate analysis scheme.

Following a preliminary study of Caumont et al. (2010), mainly performed with a research version of a nonhydrostatic mesoscale assimilation system, this paper describes the implementation of radar reflectivity assimilation in the operational AROME system, including adaptations and evaluations. Different assumptions had to be made to the observation operator, as well as to the 1D methodology in order to adapt them to the parallel computing environment of the AROME code. Moreover, scientific compromises were necessary in a cycled assimilation context. Results are shown from a preoperational version of the radar reflectivity assimilation in the AROME model. They are complemented by tests with an operational configuration. Section 2 provides a description of the radar products, tailored for assimilation purposes, the specific preprocessing, and usage in the assimilation system, together with the specification of associated error statistics. The $1 \mathrm{D}+3 \mathrm{D}-$ Var method is detailed in section 3, including descriptions of the observation operator for reflectivities, and of the $1 \mathrm{D}$ method, with a study of its behavior that leads to necessary screening decisions. The results of the assimilation experiments that are presented in section 4, mainly consist of studying the impact on analyses and evaluating conventional and precipitation forecast scores. Finally, results are summarized and discussed in section 5 by highlighting the benefits and weaknesses of this assimilation system.

\section{Observations}

\section{a. The French radar network}

The French radar network of Météo-France (ARAMIS) currently comprises $18 \mathrm{C}$ - and $6 \mathrm{~S}$-band weather radars, 13 of them having polarimetric capability. At the time of the experiments presented in this paper, Météo-France operated 10 polarimetric weather radars, 9 at the $\mathrm{C}$ band and one at the $\mathrm{S}$ band (Fig. 1) and the ARAMIS network 
comprised $17 \mathrm{C}$ - and $7 \mathrm{~S}$-band radars. In the last years, the scanning strategy has been adapted for assimilation purposes. It consists of a 15-min supercycle containing three 5 -min cycles. The lowest elevation angles are scanned at each cycle while new high elevations are added and only scanned once in a supercycle. This scanning strategy allows us to give rather complete volumetric scans thanks to different plan position indicators (PPIs) ranging between $2^{\circ}$ and $11^{\circ}$ and depending on the radar. Raw data are available in a binary universal form for the representation of meteorological data (BUFR) format, defined at Météo-France, with a 1-km spatial resolution within a $512 \times 512 \mathrm{~km}^{2}$ domain (Cartesian grid). Each file contains values for one elevation of reflectivity, radial wind (for data coming from one of the 16 Doppler radars), and data status. The results presented herein were obtained using observations, recorded and archived in real time by Météo-France in Toulouse, France, since August 2007. That is, reflectivity data from the 24 radars were assimilated in the experiments presented in this paper, but several scans and/or azimuths were excluded from the assimilation system through a data preprocessing discussed in the next paragraph.

\section{b. Reflectivity preprocessing}

The raw reflectivities are preprocessed to exclude data with gross errors. For that purpose, each raw datum contains information, which allows us to distinguish precipitation from nonprecipitating good pixels, clear-sky echoes, sea clutter, and anomalous propagation (anaprop). In particular ground clutters are filtered either from climatology map or from low values of the standard deviation of reflectivity. The information on echo types is used to remove nonmeteorological pixels, and to tune observation error statistics for the assimilation system (see the next paragraph). An estimation of the attenuation by rain is provided by the Hitschfeld-Bordan method (Hitschfeld and Bordan 1954). It prevents us from using pixels that are strongly attenuated by heavy rain. An initial sampling of the data is performed at $5 \mathrm{~km}$ in order to reduce the amount of reflectivity observations in the system. This first preprocessing is justified by the horizontal scale of the background-error structure functions $(\approx 15 \mathrm{~km})$ of the AROME model (Brousseau et al. 2011).

In addition to this preprocessing, a number of thresholds on reflectivity values have been set to eliminate most of the pixels contaminated with ground echoes. When many pixels are identified as anaprop (above $500 \%$ of the number of static ground pixels), minimum thresholds for rainy information are introduced: below $3600 \mathrm{~m}$ (above mean sea level) and for all radars, pixels with reflectivity values lower than $15 \mathrm{~dB} Z$ are discarded, while above $3600 \mathrm{~m}$ (above mean sea level), pixels are discarded when reflectivity values are lower than 8 and $0 \mathrm{~dB} Z$ for S-band and C-band radars, respectively. These thresholds are assumed constant, but in reality, they depend on the radar and on the weather situation: in preconvective situations, these values can be very high (compatible with the current choices) but they can be slightly smaller in winter.

Concerning the beam blockage, a choice has been made not to correct the raw data. Instead, a pragmatic approach is applied: it consists of blacklisting data that are potentially affected by beam blockage. In practice, the pixels corresponding to the azimuthal sector and elevation identified as partial beam blocked areas (by using maps of partial masks) are removed from data assimilation. However, a number of clean pixels can be wrongly rejected (i.e., in front of mountains). An alternative approach could be to consider the beam blockage in the observation operator for radar reflectivities by modeling the weather beam topographical blockage (Bech et al. 2007). So far the first results are not satisfactory compared to our pragmatic approach (Haase et al. 2007).

\section{c. Use of "nonrainy" observations}

The assimilation method (1D+3D-Var described hereafter) is also efficient when the model background is nonrainy. Indeed, it is possible for the model to create precipitation (in the first time step of the forecast after the analysis) when the model first guess is not producing any precipitation at observation location. Preliminary tests without using the no-rain signal led to predominantly positive humidity increments and have confirmed that symmetrically it was fundamental to assimilate the no-rain information to suppress spurious convection (Wattrelot et al. 2008) and avoid the spatial extent of positive humidity analysis increments (Wattrelot 2009). But in order to properly use the no-rain information, the minimum detectable signal from each radar must be known. This value corresponds to a minimum power $P_{\text {noise }}$, which can be detected by the radar. The power $P_{r}$ received by the radar depends on its characteristics, but what is used in practice is the "equivalent reflectivity factor" linked to the received power $P_{r}$ by the following formula (Doviak and Zrnic 1984) or (Sauvageot and Coulomb 1982):

$$
Z_{e}\left(\mathbf{r}_{0}\right)=10 \log \left[\frac{r_{0}^{2} P_{r}\left(\mathbf{r}_{0}\right) / C}{1 \mathrm{~mm}^{6} \mathrm{~m}^{-3}}\right],
$$

where $\mathbf{r}_{0}$ is the vector of length $r_{0}$ that links the radar emitting antenna to the center of the resolution volume, and $C$ is the radar constant that depends on the radar characteristics. The equivalent reflectivity (in $\mathrm{dBZ}$ ) is a relative quantity compared at the threshold value of $1 \mathrm{~mm}^{6} \mathrm{~m}^{-3}$. For a nonattenuating environment, Eq. (1) allows us to write the minimum detectable reflectivity 


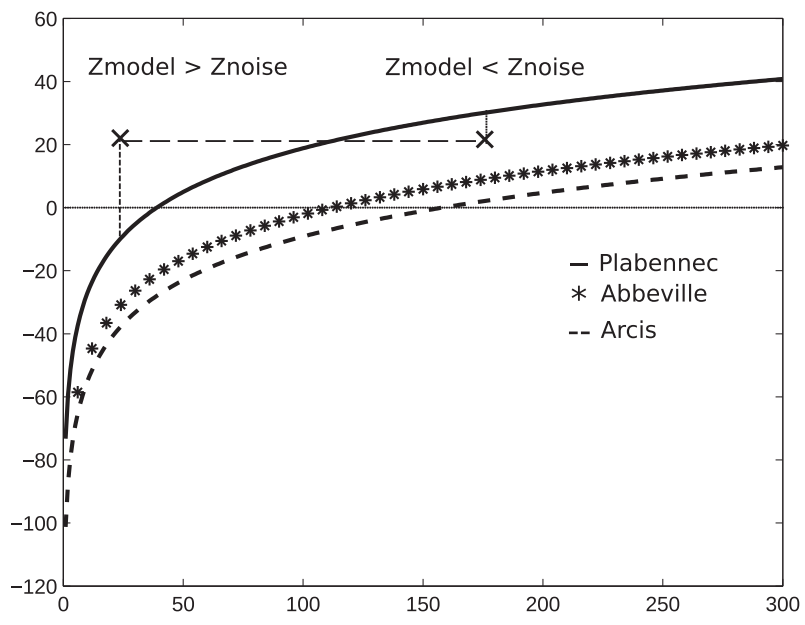

FIG. 2. Minimum detectable reflectivity as a function of range for three radars (shown as the three different line types): example of different status of $Z_{\text {model }}$ following its position compared to the noise's curve of the assimilated radar as defined in Table 1 (see text for explanations).

factor $Z_{\text {noise }}$ as a function only of the distance from the radar $r_{0}$ :

$$
\begin{aligned}
Z_{\text {noise }}\left(r_{0}\right) & =P_{\text {noise }}(\mathrm{dBm})+20 \log \left(r_{0}\right)-C(\mathrm{dBm}) \\
& =20 \log \left(\frac{r_{0}}{r_{c}}\right)
\end{aligned}
$$

where $r_{c}=10^{\left(C-P_{\text {noise }}\right) / 20}$ is the characteristic range from the radar where $Z_{\text {noise }}$ becomes positive. So, the minimum detectable signal depends on the range from the radar and on a specific distance $r_{c}$ function of the radar characteristics (Fig. 2). The distinction between rain and no rain is easy with the model background since it only depends upon the existence of precipitating hydrometeors. To make a meaningful comparison between observation and model counterparts in all situations, very low values of reflectivity simulated by the model $Z_{\text {model }}$ are set to the minimum detectable value of the radar. Indeed, if the model hydrometeor contents are nonzero, the simulated reflectivity $Z_{\text {model }}$ will be significant, even with very low values, and has to be used differently according to the observation value $Z_{\text {radar }}$. A comparison against an observed value at the minimum detection level $\left(Z_{\text {radar }}=Z_{\text {noise }}\right)$ indicates that there is no rain observed by the radar above this value. Since the radar cannot provide information below $Z_{\text {noise }}$, the simulated reflectivity $Z_{\text {model }}$ is set to this threshold in order to avoid spurious corrections. The different possible situations are summarized in Table 1 .

\section{d. Errors}

To retrieve humidity profiles from columns of reflectivities, it is necessary to specify observation error statistics. These errors originate from the observation operator and from the reflectivity measurements. Vertical correlations of reflectivity observations errors are not taken into account. Therefore, the covariance matrix of observation errors $R_{Z}$ used in the 1D Bayesian inversion is diagonal. At each level, the standard deviation $\sigma_{z}$ is set to $0.2 \mathrm{dBZ}$ (additional details on this specification are given in section $3 b$ ). In theory, these errors must take into account the different sources coming from the measurement [e.g., undetected anomalous propagation (anaprop)], attenuation by precipitation. Despite some arbitrariness in the specification of $\sigma_{z}$, preliminary tests have shown that the results of the $1 \mathrm{D}+3 \mathrm{D}-\mathrm{V}$ ar experiments were not so sensitive to this value. It appears more important to specify accurately the observation error statistics of the humidity retrievals from the $1 \mathrm{D}$ inversion into the $3 \mathrm{D}-\mathrm{Var}$, since they determine confidence given to the pseudoobservations. In particular, an increase of the measurement uncertainty with the distance from the radar (because of the beam broadening effect and propagation effects) is taken into account by applying the following pseudo-observation standard deviation:

TABLE 1. Description of the various cases of rain assimilation: "No rain observed" is the radar reflectivity observation at the noise's level $Z_{\text {noise }}$ as defined by Eq. (2) and "No rain simulated" includes either "nonrainy" simulated reflectivity (no hydrometeor in the model, leading to the simulated reflectivity set at the arbitrary value $-120 \mathrm{~dB} Z$ ) or "rainy" simulated reflectivity below the noise's level $Z_{\text {noise }}$.

\begin{tabular}{lcc}
\hline \hline Cases & Definition & Decision \\
\hline $\begin{array}{l}\text { No rain observed (NoRainO)/ } \\
\text { no rain simulated (NoRainS) }\end{array}$ & $Z_{\text {radar }}=Z_{\text {noise }}$ and $Z_{\text {model }} \leq Z_{\text {noise }}$ & $\begin{array}{c}\text { No assimilation: when } \forall i \in[1, \text { nelev }] \\
\text { No rain observed (NoRainO) } / \\
\text { rain simulated (RainS) }\end{array}$ \\
$\begin{array}{l}\text { Rain observed (RainO) } / \\
\text { no rain simulated (NoRainS) }\end{array}$ & $Z_{\text {radar }}=Z_{\text {noise }}$ and $Z_{\text {model }}>Z_{\text {noise }}$ & Drying \\
$\begin{array}{l}\text { Rain observed (RainO) } / \\
\text { rain simulated (RainS) }\end{array}$ & $Z_{\text {radar }}>Z_{\text {noise }}$ and $Z_{\text {model }} \leq Z_{\text {noise }}$ & Moistening \\
& $Z_{\text {radar }}>Z_{\text {noise }} \& Z_{\text {model }}>Z_{\text {noise }}$ & Adjustment of rain (drying or moistening) \\
\hline
\end{tabular}




$$
\sigma_{o}^{\mathrm{RH}}=0.15+\frac{0.25 \times d}{160} .
$$

Therefore, the pseudo-observation error of relative humidity retrievals varies between $15 \%$ and $40 \%$ according to the distance from radar [expressed in kilometers in the Eq. (3)], and profiles are only taken within a $160-\mathrm{km}$ radius. The error correlations between the retrieved profiles are also neglected but a thinning is performed to justify this approximation.

\section{The $1 \mathrm{D}+3 \mathrm{D}-$ Var reflectivity assimilation algorithm}

\section{a. Reflectivity observation operator}

By definition, the radar reflectivity factor $Z$ is a physical parameter (the sixth power of the hydrometeor diameter over all hydrometeors in a unit volume), which is independent of the radar characteristics and has meteorological significance (Doviak and Zrnic 1984). However, radar meteorologists have introduced the equivalent reflectivity factor $Z_{e}$, which corresponds to a received signal of the same power but for liquid water scatterers under specific assumptions on backscattering and antenna's radiation pattern as described by Probert-Jones (1962). To assimilate an equivalent reflectivity factor, still referred to as radar reflectivity, the NWP model must have the capability to simulate a realistic counterpart of the observed value. The observation operator that simulates radar reflectivities has been adapted from the Méso-NH "radar simulator" described in Caumont et al. (2006). Its goal is to simulate accurately the horizontally polarized electromagnetic pulse backscattered by the hydrometeor targets in the direction of the radar antenna. The computations and assumptions are divided in two parts. The first one concerns the computation of radar reflectivity on model grid points. In AROME this is done at each model level after a horizontal bilinear interpolation of the simulated hydrometeors at observation location. ${ }^{1}$ The second part is the definition of the sampling resolution volume of the radiation, which contributes most to the returned power.

\section{1) THE RADAR REFLECTIVITY AT EACH MODEL LEVEL}

In the AROME observation operator, the backscattering cross section $\sigma(D, \mathbf{r})$ of particles of diameter $D$ at the distance vector to the radar $\mathbf{r}$ is computed from the

\footnotetext{
${ }^{1}$ This interpolation by grid point is possible because the horizontal size of the radar gate is considered lower than the model grid mesh.
}

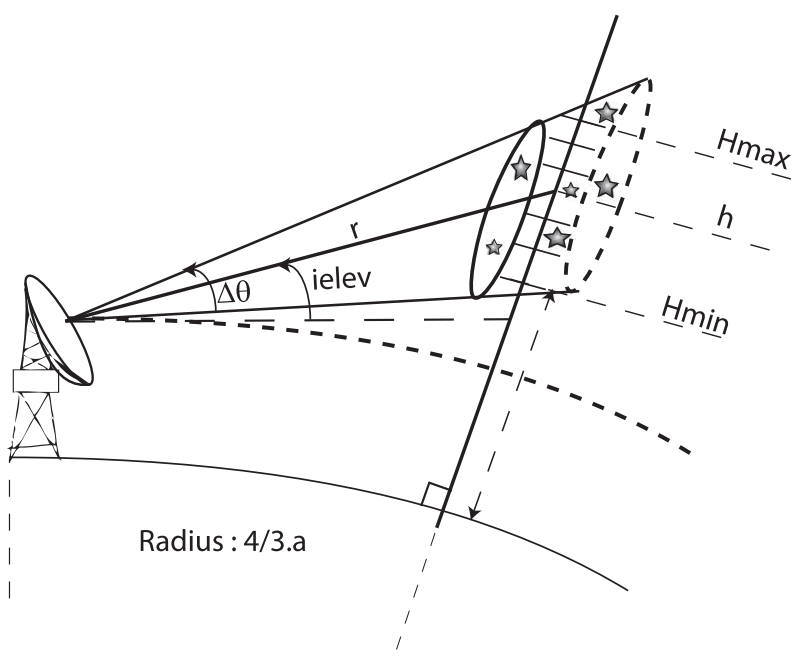

FIG. 3. Schematic diagram of the radar reflectivity observation operator. The radar beam propagates along a straight ray path in an atmosphere over a fictitious Earth with an equivalent radius $4 / 3 a$. The shaded area represents the volume resolution with model levels.

Rayleigh method. This assumption is valid when the hydrometeor diameter is sufficiently small compared to the radar wavelength. More sophisticated methods (such as volumetric methods) are available in the "Méso-NH radar simulator," but the Rayleigh scattering approximation is reasonable for S and C-band radars (Caumont et al. 2006). The integration on the model grid requires the knowledge of the hydrometeor size distributions $N(D, \mathbf{r})$. The same distributions as in the Méso-NH radar simulator have been used for the observation operator in AROME since both share the same microphysical scheme (Caniaux et al. 1994; Pinty and Jabouille 1998) that considers the following hydrometeor types: cloud water, rainwater, graupel, snow, and primary ice. Since cloud water gives very small reflectivities (typically lower than $-10 \mathrm{dBZ}$ ), it is not considered in the observation operator. Therefore, the radar reflectivity $z_{e}(r, h)$ at each model level is computed as

$$
z_{e}(r, h)=\sum_{j \in \text { type }} \frac{\left|K_{j}\right|^{2}}{\left|K_{w}\right|^{2}} \int_{D_{\min }}^{D_{\max }} N_{j}(D, r, h) D^{6} d D,
$$

where $\left|K_{j}\right|^{2}$ is the dielectric factor for the precipitation hydrometeor type $j,\left|K_{w}\right|^{2}$ is the dielectric factor of water, and $N_{j}(D, r, h)$ is the number of particles of diameter $D(m)$ for this type, at the altitude $h$ of the considered model level. Under these assumptions, the radar reflectivity $z_{e}$ depends only upon the relative permittivity of the hydrometeor scatterers and not upon the radar wavelength. The distance $r$ to the radar is considered constant on the model reflectivity profile over the resolution volume (Fig. 3). 
2) THE SIMUlated RADAR REFLECTIVITY IN THE RESOLUTION RADAR VOLUME

Regarding the definition of the resolution volume, some assumptions on the geometry of the radar beam have been adopted: the earth's curvature has been taken into account and a constant, climatological vertical gradient of the refractivity index is assumed. Under these assumptions, the height of the curved radar beam is the same as that from a straight ray path propagating in a homogeneous atmosphere of a fictious planet with an equivalent radius $a_{e}=4 / 3 a$ with the earth's radius (Fig. 3) (Doviak and Zrnic 1984). This last hypothesis corresponds to the model of the "effective radius of the earth." This allows us to localize the altitude of the radar beam, but only as a function of the range from the radar. However, this assumption is not valid when the vertical gradient of humidity is weak (temperature inversion at low elevations) or very strong (midlevel advection of humidity). Therefore, it is necessary to detect anomalous propagation before the assimilation processing as pointed in section $2 \mathrm{~b}$.

The emitted energy of the radar beam is confined into a conical beam. The resolution volume is radially determined by the sampling process and orthoradially defined by the antenna's radiation pattern. Since gate lengths are on the order of $250 \mathrm{~m}$ and the $-3-\mathrm{dB}$ beamwidth is at most on the order of the model grid mesh size in the horizontal, there is no need to integrate model fields along the horizontal direction, which is a significant advantage for the AROME code parallelization. Also, to keep a good level of performance on parallel computers, the attenuation of the reflectivity by hydrometeors along the radar beam path is not taken into account, which avoids too much message passing between processing units. Sensitivities studies have shown that attenuation was crucial for reflectivity signals from X-band radars, and sometimes from C-band radars. Therefore, it is important to detect such attenuation before the assimilation as pointed in section $2 \mathrm{~b}$.

In the observation operator for AROME, the power density function is described by a Gaussian function to represent the main lobe as suggested by Probert-Jones (1962). The side lobes are not simulated: their power is neglected because for the French radars it is at least $20 \mathrm{~dB}$ smaller than the maximum power of the main lobe. However, the hydrometeors are not considered uniformly distributed in the resolution volume and because of the radar beam broadening with the distance from the radar, the variations of reflectivities within the resolution volume have to be taken into account in the vertical. As in the Méso-NH radar simulator, the integration is done in the vertical direction through a weighted sum of the reflectivities in the considered vertical profile. Therefore, the radar reflectivity depends on the antenna aperture (one of the radar characteristics) at the distance $r$ from the radar and can be written as

$$
Z_{e}(\mathbf{r})=10 \log \left[\frac{10^{18}}{1 \mathrm{~m}^{3}} \frac{\int_{H_{\min }}^{H_{\max }} z_{e}(r, h) \exp \left\{-8 \ln 2\left[\frac{\theta(h)-i_{\text {elev }}}{\Delta \theta}\right]^{2}\right\} d h}{\int_{H_{\min }}^{H_{\max }} \exp \left\{-8 \ln 2\left[\frac{\theta(h)-i_{\text {elev }}}{\Delta \theta}\right]^{2}\right\} d h}\right],
$$

where $i_{\text {elev }}$ is the elevation of the radar beam, $\theta(h)$ is the apparent elevation at an altitude of $h, \Delta \theta$ is the $3-\mathrm{dB}$ beamwidth for one-way transmission, $H_{\min }\left(H_{\max }\right)$ corresponds to the lowest (highest) altitude of the model level in the antenna aperture, and close to the value $i_{\text {elev }}-\Delta \theta / 2$ (and $i_{\text {elev }}+\Delta \theta / 2$ ).

\section{b. $1 D$ method}

Reflectivities depend directly upon hydrometeor contents, but the latter are not in the AROME's 3D-Var control variable. Furthermore, initialization of these species is not expected to have significant impact on short-range forecasts because of their minor contribution in supplying convection and also from their lack of predictability (Fabry and Sun 2010; Fabry 2010; Wang et al. 2012, 2013a). It seems, therefore, more efficient to modify variables such as humidity or temperature. For that purpose, a 1D Bayesian retrieval of relative humidity columns from reflectivity columns has been developed upstream of the 3D-Var. The Bayesian formalism allows us to retrieve the most probable relative humidity vertical profile, given a vertical profile of observed reflectivity and a database of consistent reflectivity vertical profiles by using the model state in the vicinity of the observation (Caumont et al. 2010). Significant technical modifications are done in the massively parallel code AROME in order to use a consistent database in the 1D Bayesian inversion.

The methodology described in detail in Caumont et al. (2010) is summarized hereafter. Let the vector $\mathbf{x}$ represent a model vertical profile to retrieve, $\mathbf{x}_{\text {true }}$ denotes the true state vector, and the vector $\mathbf{y}_{o}$ represents a set of 
available observations. The best estimate of $\mathbf{x}$ given the set of observations $\mathbf{y}_{o}$ can be written by using Bayes's theorem:

$$
\mathbf{E}(\mathbf{x})=\int \mathbf{x} P\left(\mathbf{y}-\mathbf{y}_{o} \mid \mathbf{x}=\mathbf{x}_{\text {true }}\right) P\left(\mathbf{x}=\mathbf{x}_{\text {true }}\right) d \mathbf{x}
$$

A first approximation can be made by replacing the integral expression by a finite and discretized sum. It is possible if a sufficiently large database of atmospheric profiles with associated simulated counterparts (from the background in our case) is available. Moreover, if we assume that the errors of the observations $\mathbf{y}_{o}$ and of the simulated observations $\mathbf{y}$ are Gaussian and uncorrelated, Eq. (6) can be simplified. In our particular case, for each observed column of reflectivity $\left(\mathbf{y}_{Z}\right)$, a column of relative humidity pseudo-observations $\left(\mathbf{y}_{\mathrm{po}}^{\mathrm{HU}}\right)$ can be computed by a linear combination of simulated columns taken from the model background state weighted by a function of the difference between observed and simulated reflectivities:

$$
\mathbf{y}_{\mathrm{po}}^{\mathrm{HU}}=\sum_{i} \mathbf{x}_{i}^{\mathrm{HU}} \frac{\exp \left[-\frac{1}{2} J_{\mathrm{po}}\left(\mathbf{x}_{i}\right)\right]}{\sum_{j} \exp \left[-\frac{1}{2} J_{\mathrm{po}}\left(\mathbf{x}_{j}\right)\right]}
$$

with

$$
J_{\mathrm{po}}(\mathbf{x})=\left[\mathbf{y}_{Z}-H_{Z}(\mathbf{x})\right]^{\mathrm{T}} \mathbf{R}_{Z}^{-1}\left[\mathbf{y}_{Z}-H_{Z}(\mathbf{x})\right],
$$

where $\mathbf{x}_{i}^{\mathrm{HU}}$ are columns of model relative humidity taken from the background state in the vicinity of the observation, $H_{Z}(\mathbf{x})$ is the simulated reflectivity by the radar simulator, and $\mathbf{R}_{Z}$ is the observation error covariance matrix.

In the AROME operational configuration and experiments presented hereafter $\mathbf{R}_{Z}$ will be a diagonal matrix with one unique term equal to $n \times \sigma_{z}^{2}$, where $n$ is the number of observations in a vertical profile. The observation error is inflated by the number of elevations to give identical weights to the same model profiles for every observation column whatever the number of elevations to retrieve. The $\sigma_{z}$ values act in the 1D Bayesian inversion as weights on the model profiles closest to the observed column: if the observation errors are too large, the retrieval will be a weighted average of many model neighboring profiles and therefore, it could be biased toward the mean value of the profiles from the database. To prevent from such effect, a very low value of $\sigma_{z}$ is chosen (at $0.2 \mathrm{dBZ}$ ). The consequences of this choice are detailed in the next paragraph.

The method assumes that model profiles (in the vicinity of the observation and used to invert reflectivities) follow the same probability density function as that of the real profiles found in nature (or at least in the region where the inversion is applied). Using model profiles in the vicinity of the observation will constrain the solution and avoid an incorrect retrieval that could occur because of finite summation or implicit ambiguity of the model profiles for the nonrainy observations. Experiments were undertaken in order to examine the sensitivity of the results to the chosen vicinity, and to the number and to the spatial density of the profiles. Results indicate that above $100 \mathrm{~km}$ around the radar observation and above 80 profiles, ${ }^{2}$ the dependence of retrievals on the number of profiles and research area becomes very low (not shown). However, the behavior of the 1D method may depend upon the background profiles and must be checked before assimilation of the retrieval in the 3D-Var AROME.

\section{c. Description of the quality controls}

\section{1) A PRIORI QUALITY CONTROLS}

The first quality control (QC) is based on reflectivity observations minus guess departures averaged on each column. This QC enables us to check observation against the model counterpart. The new positioning of misplaced or unpredicted precipitation patterns means that the QC of reflectivity must allow large departures in the system: in practice a value of $40 \mathrm{dBZ}$ has been chosen. The similar QC for humidity retrievals takes into account the background-error statistics for relative humidity that are flow dependent in the screening, and an observation error set to $15 \%$ for simplicity [the dependency with radar range presented in Eq. (3) before is only used in the 3D-Var minimization in order to filter out most dubious data]. After the initial data reduction $\left(5 \times 5 \mathrm{~km}^{2}\right)$ and before entering the minimization process, a thinning is performed, to avoid horizontal correlation of observation errors. In each $15 \times 15 \mathrm{~km}^{2}$ box, the selected profile corresponds to the one having the most important number of elevations that passed the QC.

Other QC have also been introduced to improve the consistency of the retrievals. One limitation of the 1D statistical method is that the retrieved vertical profiles depend on what the model is able to simulate at the time of analysis. For instance, if precipitation is observed in an area where no rain is triggered by the model, the method will not be able to find neighboring columns with significant reflectivities. This case occurs in particular when $\sigma_{z}$ is very small. Indeed, the method favors model columns

\footnotetext{
${ }^{2}$ Sensitivity studies with different domain sizes have been performed and a moving window of $9 \times 9$ columns uniformly distributed in a $100-\mathrm{km}$ square centered on the observation point is used in the operational version.
} 
that resemble most the observation and the weights of other columns are much lower. As a consequence, pseudo-observations cannot be produced when the overall background in the vicinity of the observation is not close enough to the observation (the weights are almost equal to zero for every model profile), which is a desirable feature. Sensitivity studies of the 1D+3D-Var assimilation method to the observation error standard deviation $\sigma_{z}$ were already carried out in Caumont et al. (2010) with similar effects. In the original version presented by Caumont et al. (2010) for cases where no "rainy" pseudo-observations could be computed by the 1D inversion an additional correction was made that consisted of a humidity adjustment procedure by applying saturation above the model condensation level, where reflectivities are observed but none can be retrieved by the 1D-Bayesian inversion. Although it showed promising results on a case study (Caumont et al. 2010), this adjustment procedure has not been selected for operational implementation. Indeed, given the high spatial variability of heavy convective precipitating patterns, this latter procedure would require a symmetrical artificial drying to avoid creating a positive bias of humidity when the model state is completely saturated in the neighborhood of the observation. By not applying this procedure when using a low value of $\sigma_{z}$ can lead to the absence of any retrieval for some reflectivity observations. This can be interpreted as an implicit quality control that removes observations not suitable for assimilation. The main drawback of this approach is the inability to create rain if the model has a completely "dry" state in the vicinity of a rainy observation, which happens very rarely.

\section{2) BEHAVIOR OF THE 1D BAYESIAN METHOD}

To shift, create, or remove precipitating patterns, it is necessary to give less weight to the standard background check QC. However, in order not to introduce data of poor quality in the assimilation, the control of the correct behavior of the $1 \mathrm{D}$ retrieval led to the definition of a new quality control. In addition to the implicit control mentioned above, the good behavior of the 1D method can be evaluated by the existence of profiles thermodynamically consistent with the observed profile. It is especially important to check the possible ambiguity of the relative humidity retrievals for nonrainy profiles. That consistency can be measured by the deviation between the reflectivities simulated with the retrieved profile and the observed ones. If these values are very close to each other, it means that the model background database contains precipitating hydrometeor information to create the rainy or nonrainy observation.

This "pseudo-analyzed" profile of reflectivity $\mathbf{Z}_{\text {pseudo_ana }}$ is a function of the specific contents of precipitating hydrometeors (rainwater, snow, graupel, and pristine ice) corresponding to a relative humidity retrieval that is obtained by the same Bayesian inversion:

$$
\begin{aligned}
\mathbf{Z}_{\text {pseudo_ana }} & =H_{Z}[\mathbf{E}(\mathbf{x})] \\
& =H_{Z}\left\{\sum_{i} \mathbf{x}_{i} \frac{\exp \left[-\frac{1}{2} J_{\text {po }}\left(\mathbf{x}_{i}\right)\right]}{\sum_{j} \exp \left[-\frac{1}{2} J_{\mathrm{po}}\left(\mathbf{x}_{j}\right)\right]}\right\} .
\end{aligned}
$$

We then operate a simplification mainly based on practical issues: we assume the observation operator linear with respect to the precipitating hydrometeors variables, which leads to

$$
\begin{aligned}
\mathbf{Z}_{\text {pseudo_ana }} & \cong \sum_{i} H_{Z}\left(\mathbf{x}_{i}\right) \frac{\exp \left[-\frac{1}{2} J_{\text {po }}\left(\mathbf{x}_{i}\right)\right]}{\sum_{j} \exp \left[-\frac{1}{2} J_{\mathrm{po}}\left(\mathbf{x}_{j}\right)\right]} \\
& =\sum_{i} \mathbf{Z}_{\mathrm{i} \_\operatorname{sim}} \frac{\exp \left[-\frac{1}{2} J_{\mathrm{po}}\left(\mathbf{x}_{i}\right)\right]}{\sum_{j} \exp \left[-\frac{1}{2} J_{\mathrm{po}}\left(\mathbf{x}_{j}\right)\right]} .
\end{aligned}
$$

Therefore, in practice, this pseudoanalyzed reflectivity column is estimated from a linear combination of reflectivity profiles $\mathbf{Z}_{\mathbf{i}_{\text {_sim }}}$ with the weights of the Bayesian inversion used to derive the relative humidity retrieval.

The 1D Bayesian inversion is controlled by the relative differences between the analyzed and observed reflectivities. Large differences between $\mathbf{Z}_{\text {pseudo_ana }}$ and $\mathbf{y}_{Z}$ reveal that the inversion is not able to provide pseudo-observations that are consistent with observations in terms of reflectivity and the corresponding retrieved profiles are not assimilated in the 3D-Var AROME. In most situations, the correlation between $\mathbf{Z}_{\text {pseudo_ana }}$ and $\mathbf{y}_{Z}$ is already quite good, larger than 0.9 (Fig. 4), from the experiment OREFLEC introduced hereafter in section $4 \mathrm{a}(2)$.

\section{3) A posteriori QUALITY CONTROLS}

The correlation between the observation minus guess relative humidity departures and the observation minus guess departures of reflectivity is positive but not very high (0.59, Fig. 5). This result was expected as it is well known that the link between humidity and precipitation is not linear: for instance, several precipitating states can be found for a same humidity state, which is even more true for dry profiles because of the ambiguity of nonprecipitating profiles. Intuitively, it is expected that the total column water vapor increments should be coherent 


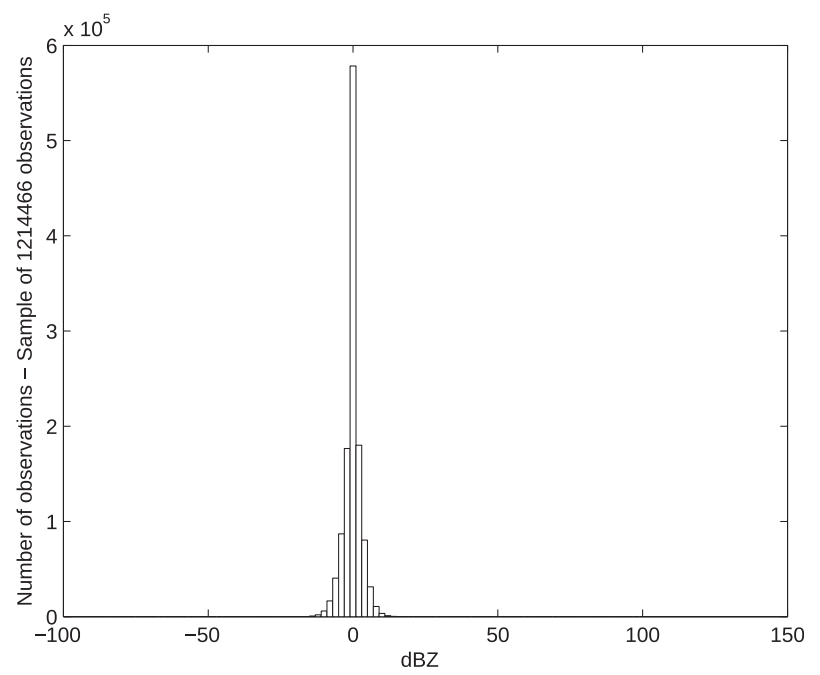

FIG. 4. Histogram of analyzed reflectivity minus observed reflectivity from 2100 UTC 22 Feb to 0000 UTC 28 Feb 2010 (42 assimilation cycles) (OREFLEC experiment). The sample comprises 1214466 observations entering the 1D Bayesian inversion. The correlation between the analyzed reflectivity and the observed reflectivity is 0.9678 .

with the reflectivity departures as found for the assimilation of all-sky radiances (Bauer et al. 2010; Geer et al. 2010).

The positive correlation indicates that indeed the physical consistency is achieved. Positive (negative) reflectivity departures; for example, too little (too much) rain in the model leads to a moistening (drying) of the model after the 1D retrieval (most of departures evolve in the same direction). Nevertheless for a significant number of profiles the reflectivity departures have an opposite sign to those of relative humidity departures. It means that the retrieval dries the model when it is expected to increase precipitation and vice versa. These cases can occur even if the pseudoanalyzed reflectivity is close to the observed one (e.g., the 1D method has well converged). Indeed, the retrieval can provide (locally on the vertical) a reduction of humidity but with more rain than in the background. This can be realistic but in order to act efficiently on precipitating systems, other model fields (including wind convergence/divergence) have to be modified consistently in the 3D-Var analysis in particular through the cross correlations of the background-error covariance matrix. However, the current climatological specification is not particularly representative of precipitating structures as shown by Montmerle and Berre (2010). Therefore, although radial winds are assimilated consistently with pseudo-observations of relative humidity, profiles with reflectivity and relative humidity departures of opposite signs are discarded from the assimilation (profiles corresponding to the first and the last

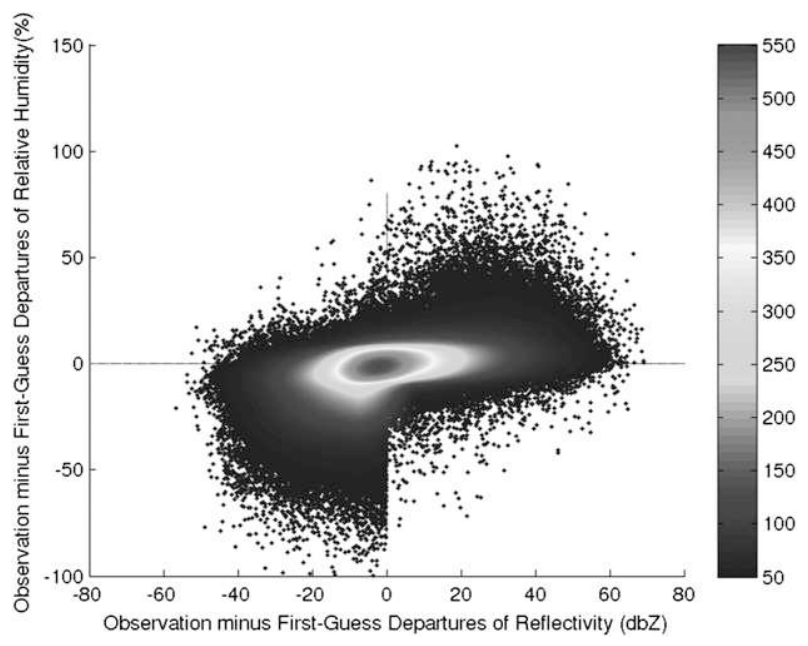

FIG. 5. Observation minus first-guess departures of relative humidity against reflectivity innovations (same period as in Fig. 4). The color scale indicates the density of observations in a circle with a fixed radius around each individual observation.

quarter of the scatterplot in Fig. 5). This latter QC is thus linked to a current weakness of the 3D-Var assimilation system that uses the $1 \mathrm{D}$ relative humidity active retrievals similarly to the other observations mostly representative of nonrainy areas (described in the experimental framework in section $4 \mathrm{a}$ ).

The active relative humidity retrieved profiles are indeed directly assimilated in the 3D-Var assimilation system as pseudo-observations at pressure levels corresponding to the altitudes of observed reflectivity pixels.

\section{1D+3D-Var evaluation}

\section{a. Experimental framework}

Two pairs of experiments are introduced hereafter to evaluate the impact of radar reflectivity assimilation in the AROME 3D-Var Rapid Update Cycle (RUC) system.

\section{1) Preoperational eXPeriments}

The main purpose of the first pair of preoperational experiments is to demonstrate the capacity of the radar reflectivity assimilation method for improving the performance of the AROME system. The configuration used in these experiments and validated over long periods has been the basis of all next operational experiments of reflectivity assimilation. These experiments are based on the first operational configuration of the AROME system (without reflectivity assimilation). The AROME system is used with a $2.5-\mathrm{km}$ mesh covering the France domain $\left(40.5^{\circ}-51.7^{\circ} \mathrm{N}, 5.2^{\circ} \mathrm{W}-11.2^{\circ} \mathrm{E}\right)$. This domain is vertically divided in 41 layers from $17 \mathrm{~m}$ above the ground up to 
TABLE 2. Definition of the experiments.

\begin{tabular}{|c|c|c|c|c|}
\hline Expt & $\begin{array}{l}\text { Preoperational expt based } \\
\text { on the first operational } \\
\text { configuration of AROME }\end{array}$ & $\begin{array}{c}\text { Tests based on a version } \\
\text { in preparation of the AROME } \\
\text { model as after } 24 \text { Nov } 2010\end{array}$ & $\begin{array}{l}\text { Assimilation } \\
\text { of reflectivity }\end{array}$ & $\begin{array}{l}\text { Improved usage } \\
\text { of the no-rain signal }\end{array}$ \\
\hline NOREFLEC & $\times$ & & & \\
\hline REFLEC & $x$ & & $x$ & \\
\hline ONOREFLEC & & $x$ & & \\
\hline OREFLEC & & $x$ & $x$ & $x$ \\
\hline OREFLECNOTUN & & $x$ & $x$ & \\
\hline
\end{tabular}

$1 \mathrm{hPa}$ and coupled to the ALADIN model. Except for radar data, the observations assimilated in the AROME 3D-Var are the same as in the ALADIN 3D-Var (Fischer et al. 2005), with the same spatial density, except for GPS zenith tropospheric delay (GPS-ZTD), which benefit from a specific station selection (Yan et al. 2009). We performed two experiments: the first one uses the operational version of AROME from which reflectivity data are discarded but with radar radial wind of improved quality $^{3}$ and the second one uses additional radar reflectivities described in section 2 . The time period begins at 0000 UTC 11 December 2008 and ends on 11 January 2009 (Table 2). These experiments are referred as NOREFLEC and REFLEC, respectively.

In the REFLEC experiment, the information about the minimum detected reflectivity is not used (because it was not provided by radar producers). As a consequence, the radiation values of reflectivity at noise level were set to an arbitrary value of $0 \mathrm{dBZ}$ up to $100 \mathrm{~km}$ in order to account for increasing noise with range (to avoid suspicious drying very far from the radar). Therefore, negative values of reflectivity identified as rain (close to the radar) are not taken into account. With such observation processing, simulated reflectivities are also thresholded at $0 \mathrm{dBZ}$ : at the observation location and also for all model profiles from the database used for the $1 \mathrm{D}$ Bayesian retrieval [Eqs. (7) and (8)].

In this configuration, the assimilation of reflectivity became operational on 6 April 2010.

\section{2) OPERATIONAL EXPERIMENTS}

The second pair of experiments refers to an intermediate system in preparation to the version of AROME, which became operational at Météo-France on 24 November 2010. This version contains a number of evolutions with

\footnotetext{
${ }^{3}$ These new radar data, which have been used since July 2009 in the operational AROME system, are characterized by an improved preprocessing, (e.g., better identification of sea clutter and clear-sky echoes, even if a number of rainy pixels are also discarded) that profits both reflectivity and radial wind.
}

respect to the preoperational experiments described above: radiances from the Infrared Atmospheric Sounding Interferometer (IASI) at 80-km thinning, an increased number of vertical levels to 60 , the direct coupling with the global model ARPEGE with a $10-\mathrm{km}$ resolution over western Europe, background-error covariances deduced from an ensemble data-assimilation technique (Brousseau et al. 2011) and a larger computational domain (with 750 and 720 physical grid points in the east-west and northsouth directions). In the first experiment, reflectivity data are introduced as described in sections $2 b$ and $2 c$, with an improved no-rain characterization using the minimum detectable reflectivity depending on the radar and the range from the radar. Reflectivity values at a noise level above $0 \mathrm{dBZ}$ are still not used. This first experiment is referred as OREFLEC. The equivalent experiment where relative humidity retrievals from radar reflectivities are not assimilated is referred as ONOREFLEC (Table 2).

Both experiments have been run over the period between 0000 UTC 1 February and 0000 UTC 28 February 2010. Experiment OREFLEC has also been run over another period (29 April to 12 May 2010) for a comparison to a third experiment that uses the reflectivity as in the preoperational experiment (i.e., without the improved characterization of the no-rain detection, but based on the same AROME configuration as OREFLEC). This last experiment is referred as OREFLECNOTUN. The three experimental designs are summarized in Table 2.

\section{b. Analysis impact}

\section{1) General BeHAVior}

First we focus on the impact of REFLEC on the relative humidity field. Figure 6 shows, for the overall AROME domain, mean and RMS values of relative humidity differences between REFLEC and NOREFLEC averaged over 1 month, from the analyses, the 3 - and the 12 -h forecasts. The assimilation of radar reflectivities brings significant information on humidity mainly between 850 and $300 \mathrm{hPa}$. The positive analysis differences predominant at $700 \mathrm{hPa}$ are kept through the forecasts up to 12-h range. The comparison between the mean and the 


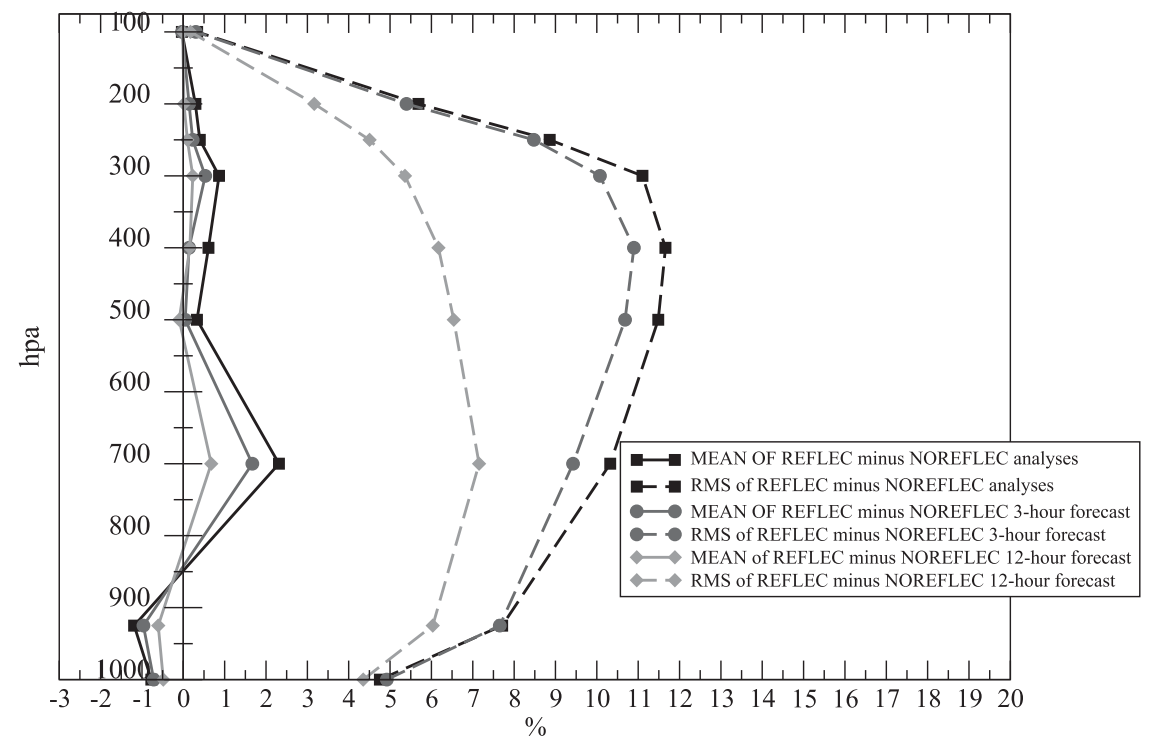

FIG. 6. Vertical profiles of analysis and forecast differences (mean and RMS) of relative humidity between REFLEC and NOREFLEC experiments for a 1-month average (11 Dec 2008-11 Jan 2009) over the AROME domain.

RMS at different altitudes shows that even though the mean differences are still positive at 400 and $500 \mathrm{hPa}$, they are smaller than at $700 \mathrm{hPa}$, while the RMS is larger. Therefore, they exhibit similar values but with more dispersion between negative and positive values than at $700 \mathrm{hPa}$, leading to as much drying as moistening in the highest troposphere, while in the midatmosphere the differences lead to much more moistening. The impact of REFLEC on the analysis differences of the humidity field is still visible up to 12 -h forecasts over the entire troposphere.

An objective evaluation of the analyses from REFLEC against NOREFLEC over the time period between 12 December 2008 and the 10 January 2009 has been done: a positive impact on the RMS of the differences of the wind field from the analyses with respect to radiosounding data has been observed (not shown) but no impact has been found for the humidity field. In a first explanation, this impact on the wind field can be induced by the 3D-Var multivariate analysis. Indeed, the cross correlations between the humidity and the wind fields were first introduced by Berre (2000), which has extended the balance operator to the coupling with moisture (multiple linear regressions) including not only dynamical links but also thermodynamic processes. However, it will be discussed in the next section that this impact cannot be due solely to the multivariate analysis.

To illustrate the behavior of the 3D-Var analysis, a scatterplot of the relative humidity (RH) 3D-Var analysis increments against the relative humidity observation minus background departures is displayed in Fig. 7 for the experiment OREFLEC. The RH field of the 3D-Var analysis is clearly constrained by the $\mathrm{RH}$ retrievals since nearly all points verify the following ranking: $\mathbf{y}_{\mathrm{po}}^{\mathrm{HU}}<$ $H\left(\mathbf{x}_{a}^{\mathrm{HU}}\right)<H\left(\mathbf{x}_{b}^{\mathrm{HU}}\right)$ or $H\left(\mathbf{x}_{b}^{\mathrm{HU}}\right)<H\left(\mathbf{x}_{a}^{\mathrm{HU}}\right)<\mathbf{y}_{\mathrm{po}}^{\mathrm{HU}}$ depending on the sign of the relative humidity departures.

These results are consistent with the recent computations of a posteriori diagnostics of the impact of observations on the analysis of the AROME 3D-Var assimilation system (Brousseau et al. 2013). They computed the reduction of the estimation error variance and showed the large impact of the radar observations on the analyzed model fields, in particular that the relative humidity pseudo-observations retrieved from the radar reflectivities contribute the most to the variance reduction of specific humidity in the midatmosphere during precipitating periods.

\section{2) BEHAVIOR FOR A SPECIFIC RADAR}

The impact on analyses of the reflectivity assimilation is only isolated by examining differences of $\mathrm{RH}$ analysis between experiments OREFLEC and ONOREFLEC for one analysis cycle (22 February 2010) starting from the same background.

The rain/no-rain distinction is illustrated in Fig. 8 for the Cherves radar (red triangle) at the elevation $0.99^{\circ}$ for this particular date. Figure 8a (Fig. 8b) shows the observed reflectivity field (the simulated counterpart of the same PPI after being thresholded according to Table 1).

From the observation side, reflectivities at noise's level are kept below $0 \mathrm{~dB} Z$ (symbol A in Fig. 8a, green pixels between -15 and $0 \mathrm{~dB} Z$ ) in order to only use realistic 


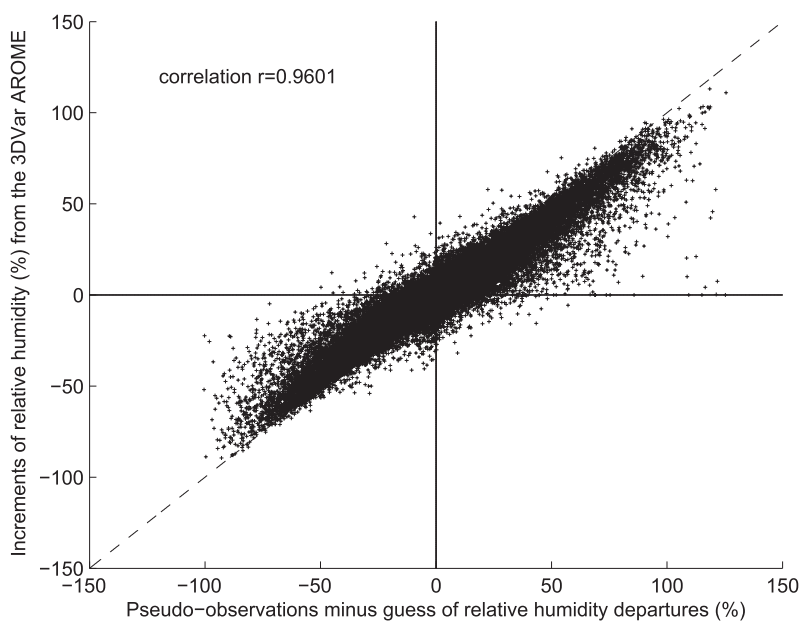

FIG. 7. Relative humidity analysis increments against relative humidity innovations (same period as Fig. 4).

values of no-rain signal. These pixels are then collected up to a limited radius corresponding at the value $r_{c}$ [Eq. (2)] and explained by this threshold of $0 \mathrm{dBZ}$.

In Fig. 8b, the simulated counterpart is leveled in the no-rain observation (symbol B) according to case 1 in Table 1. The corresponding observations are then not assimilated. For the case of absolute no-rain in the model ${ }^{4}$ but rain in the observation a moistening of the model is made according to case 3 in Table 1 (symbol C). Still on the model side, negative values of reflectivity, between -10 and $-25 \mathrm{dBZ}$ (less than $10^{-3} \mathrm{~g} \mathrm{~kg}^{-1}$ of precipitating hydrometeors) appear in an area where scattered precipitation is simulated (symbol D). The model produces finer rain than radars could ever detect. These reflectivities may correspond to very weak content of large residual droplets isolated in drying areas close to large areas of precipitation. Indeed, in clouds where droplets are growing and precipitation is created, the number of cloud droplets is sufficiently large before developing into raindrops, thus inducing a positive value of the reflectivity.

But as rain is detected in the observation at this location, the model is moistened as still in case 3 in Table 1. It is clearly a slightly "rainy" simulated reflectivity, but still referred as "no rain simulated" because the simulated value is below the noise's level of the radar observation at this location.

Figure $8 \mathrm{c}$ shows for this elevation of $0.99^{\circ}$ (most of data are in the midatmosphere around $100-\mathrm{km}$ range from the radar), the pseudoanalysis of reflectivity, which

\footnotetext{
${ }^{4}$ For numerical reasons, the reflectivity (in $\mathrm{dBZ}$ ) in the case of complete absence of precipitating hydrometeors in the model has been set at the arbitrary value of $-120 \mathrm{~dB} Z$.
}

contributes to define the active pseudo-observations of relative humidity (Fig. 8d).

Figure 9 displays for the same elevation the corresponding relative humidity pseudo-observation minus background departures and their impact on the $\mathrm{RH}$ field in the 3D-Var analysis at $700 \mathrm{hPa}$. In Fig. 9d, regions of positive and negative differences in relative humidity increments (or analysis differences because both experiments use the same background state) are well represented according to the respective positive and negative regions of departures (Fig. 9a). This case illustrates the fact that the $1 \mathrm{D}+3 \mathrm{D}$-Var methodology is able to increase or reduce humidity whatever the state of the background (Fig. 9c) and through different status of the used observations (Fig. 9b).

\section{c. Forecast evaluation}

Forecast evaluation has been carried out using model analyses as a reference. Figure 10 a shows the RMS differences in 24-h forecasts of temperature at $925 \mathrm{hPa}$ with respect to their own analyses between REFLEC and NOREFLEC for the overall time period (between 12 December 2008 and 10 January 2009). This RMS is reduced for REFLEC up to the 24-h forecast range. It indicates that the radar reflectivity observations are consistent with model forecasts, because the added information brought by the reflectivities is kept during the $24 \mathrm{~h}$. It is interesting to notice that the impact is visible for each individual forecast of the period (after the first assimilation cycles). Moreover, the forecast differences against observations as a reference generally show a positive evaluation of the impact. For example, a comparison of the model wind field at $925 \mathrm{hPa}$ against radiosoundings is shown in Fig. 10b. The RMS and the mean of such differences are reduced by REFLEC up to $12 \mathrm{~h}$ for a majority of forecasts. A similar impact is noticed over the whole troposphere for model wind forecasts. On the other hand, no impact was found on the humidity field. This improvement on temperature and wind fields is not intuitive since reflectivity observations should modify mostly the humidity field. This behavior can be explained by the cross correlations between the humidity field and the other model fields through the background-error covariance matrix as mentioned in the previous section about analysis scores. However, the AROME 3D-Var system uses a climatological multivariate backgrounderror covariance matrix deduced from an ensemblebased method (Brousseau et al. 2011), which gathers summer and winter cases in order to build statistics representative of a wide range of forecast errors. By explicitly computing the statistics in rainy areas, Montmerle and Berre (2010) have shown that using climatological covariance matrix, the coupling between the humidity 

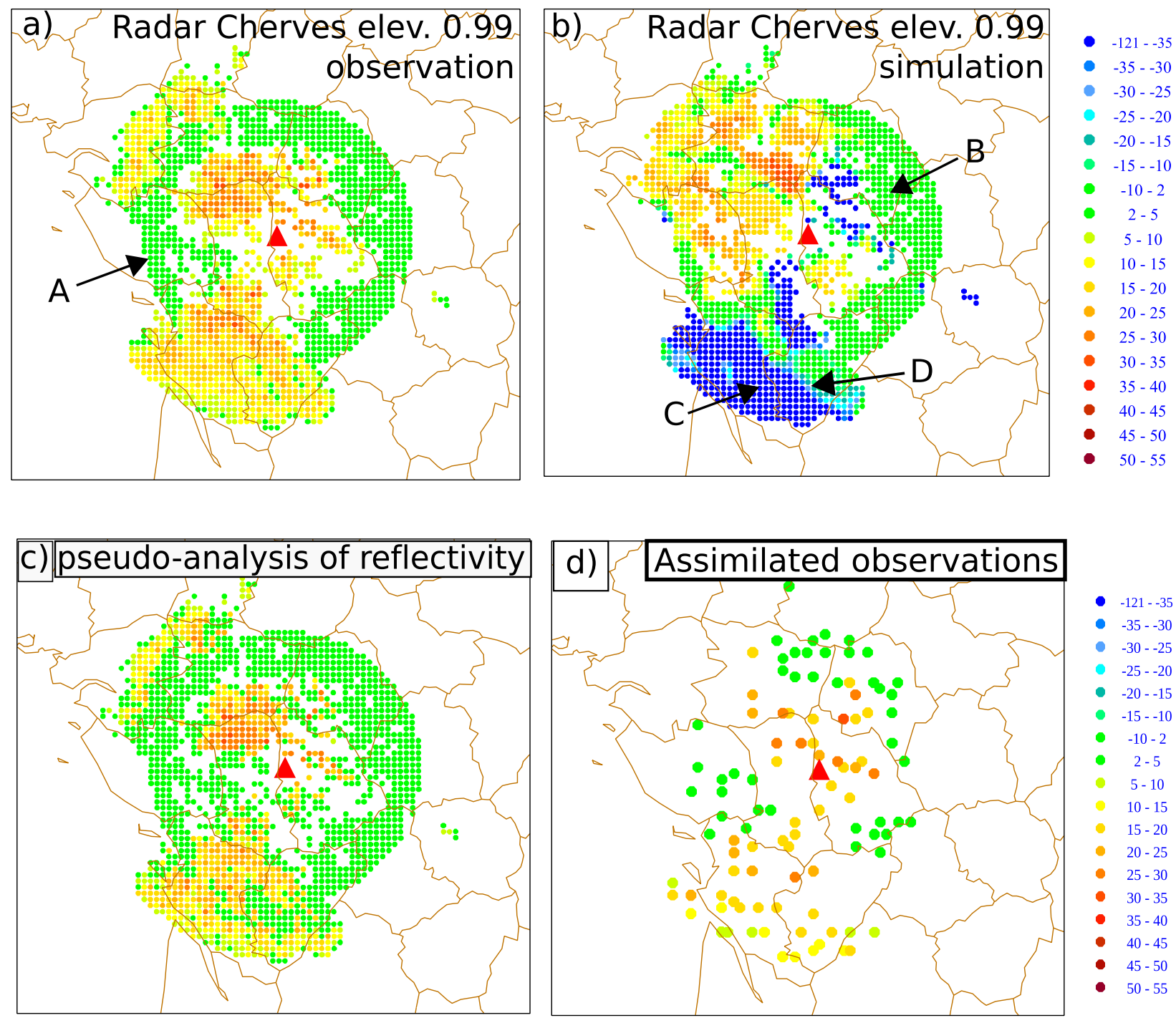

FIG. 8. (a) Observed radar reflectivity, (b) corresponding simulated reflectivities from an AROME 3-h forecast, (c) pseudoanalysis of reflectivity, and (d) active 1D Bayesian retrievals used in the 2100 UTC analysis 22 Feb 2010 from the Cherves radar at 0.99 elevation PPI (in $\mathrm{dBZ}$ ). All model fields come from experiment OREFLEC.

and unbalanced divergence could be too weak in convective areas and could provide wrongly balanced increments. Therefore, improvements are more likely caused by mutual adjustments between humidity and wind during the forecasting steps of the assimilation cycle. The cycling also provides a better usage of Doppler radial winds (Montmerle and Faccani 2009), since these observations are consistently assimilated with radar reflectivities.

The most visible impact has been noticed on precipitation forecast scores against rain gauge measurements. A positive impact is found for REFLEC for most of the forecasts of a time series of 3-h probabilistic precipitation scores (cf. Fig. 11 for the threshold of $1 \mathrm{~mm} \mathrm{~h}^{-1}$ ). The definition of each used score is described in the appendix. These categorical scores, which measure the probability of detection (POD) of rainy patterns and false alarm ratio (FAR), are improved for a lot of analysis times. Results are presented for one threshold but the short-term forecasts are visibly improved for all thresholds up to $10 \mathrm{~mm} \mathrm{~h}^{-1}$ as shown in average on Fig. 12 (above $10 \mathrm{~mm} \mathrm{~h}^{-1}$ the number of samples is too small to bring any significant conclusion). Similar results have been observed for other forecast ranges up to $12 \mathrm{~h}$.

Focus is made here on the comparison between OREFLEC and OREFLECNOTUN, which uses the same configuration as OREFLEC but without this improved no-rain characterization as described in section $4 \mathrm{a}(2)$. 

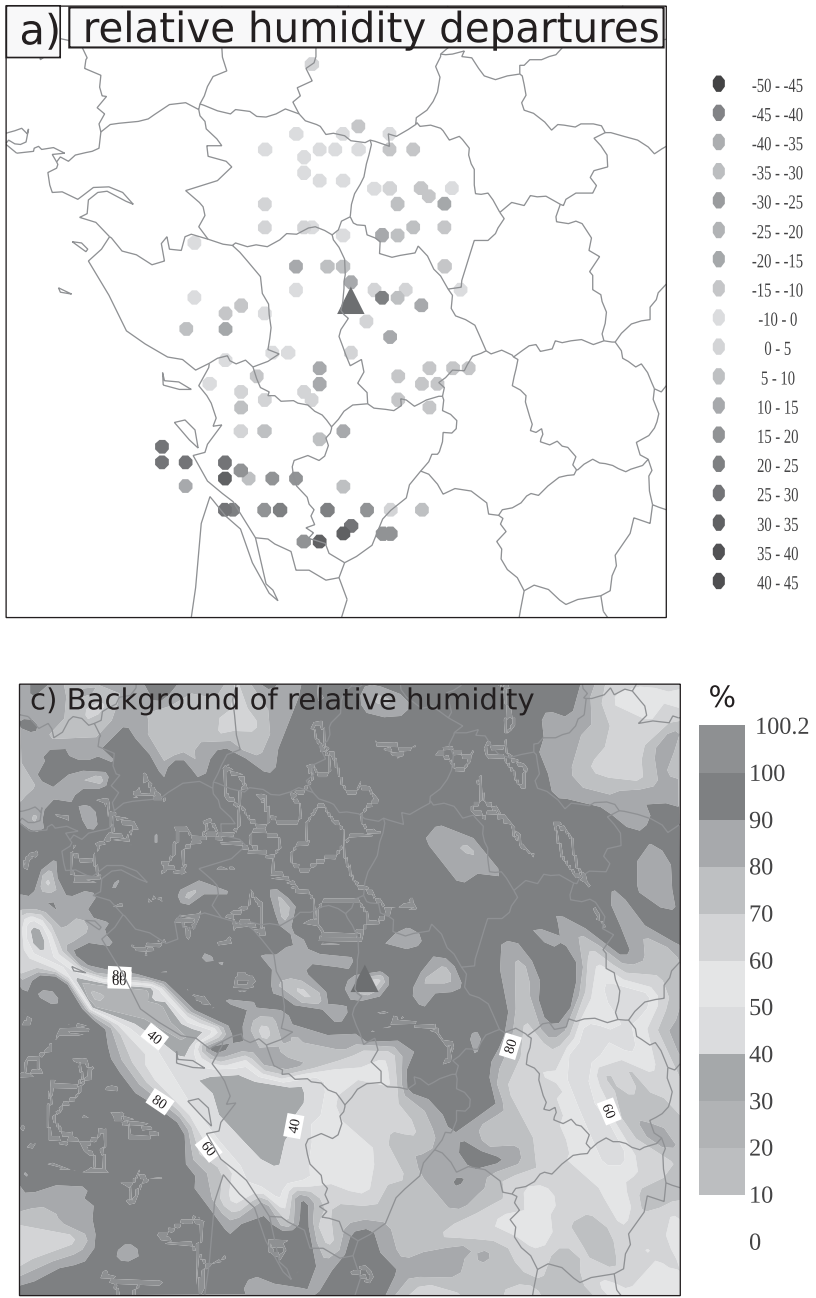
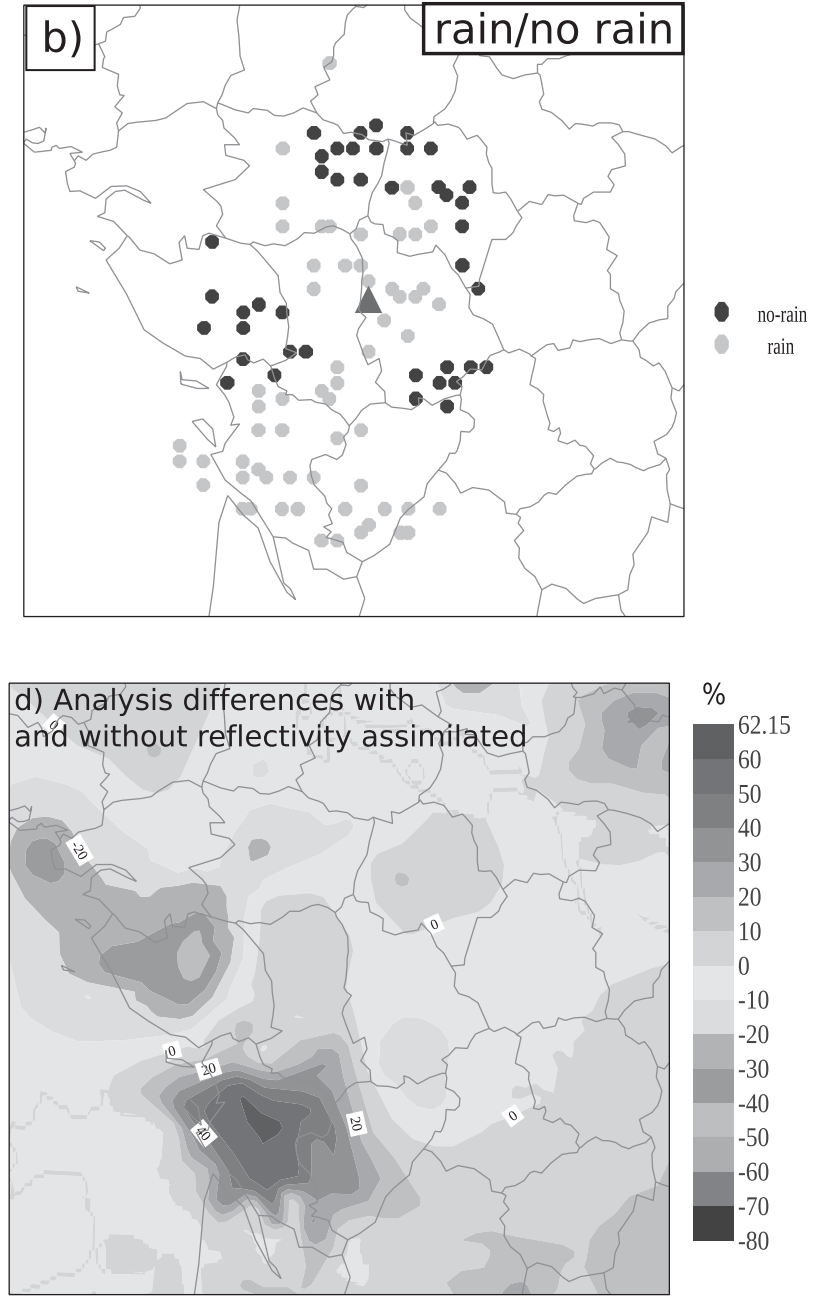

FIG. 9. (a) Observed minus background relative humidity at the same location and (b) initial status of the observed reflectivity values. At $700 \mathrm{hPa}$ : (c) background relative humidity and (d) difference in relative humidity increments between OREFLEC and ONOREFLEC (both experiments use the same background state), for the same data, radar and elevation as in Fig. 8.

The comparison does not show any significant impact on the objective conventional scores (not shown) but some impact is visible on the classical probabilistic quantitative precipitation forecast (QPF) scores. Indeed, the Fig. 13 shows a slight improvement of the probability of detection, the false alarm ratio, and the equitable threat score. The frequency bias, already close to unity, does not indicate any change in the capability to underpredict or overpredict the occurrence of rain for any specific threshold.

\section{d. Case study: Thunderstorms on the southwest of France on 5 August 2009}

The pair of experiments chosen for this case study refers to an AROME system close to the one used in REFLEC and NOREFLEC experiments but with 60 vertical levels instead of 41 . The names of the experiments are kept unchanged for simplicity. The case study is a convective situation that occurred on 5 and 6 August 2009 and the experiments are cycled every $3 \mathrm{~h}$ from 1500 UTC 14 July 2009. In the evening of 5 August 2009, convective clouds moved from Spain to the Basque country over the Pyrénées. During the night they covered the entire southwest of France and strong thunderstorms developed locally with strong gust winds over the "Pyrénées Atlantiques" and "Hautes-Pyrénées" areas. Earlier in the afternoon, temperatures were very high (above $35^{\circ} \mathrm{C}$ ) in the southwest. The evolution of thunderstorms over the southwest is significantly different between the forecasts from analysis with assimilated reflectivities and the forecasts from analysis without reflectivity. Figure 14 shows a much better reflectivity field from 3 -h forecasts in REFLEC at 2100 UTC 5 August but also at 0000 UTC 6 August where the convection, visible on the observed 

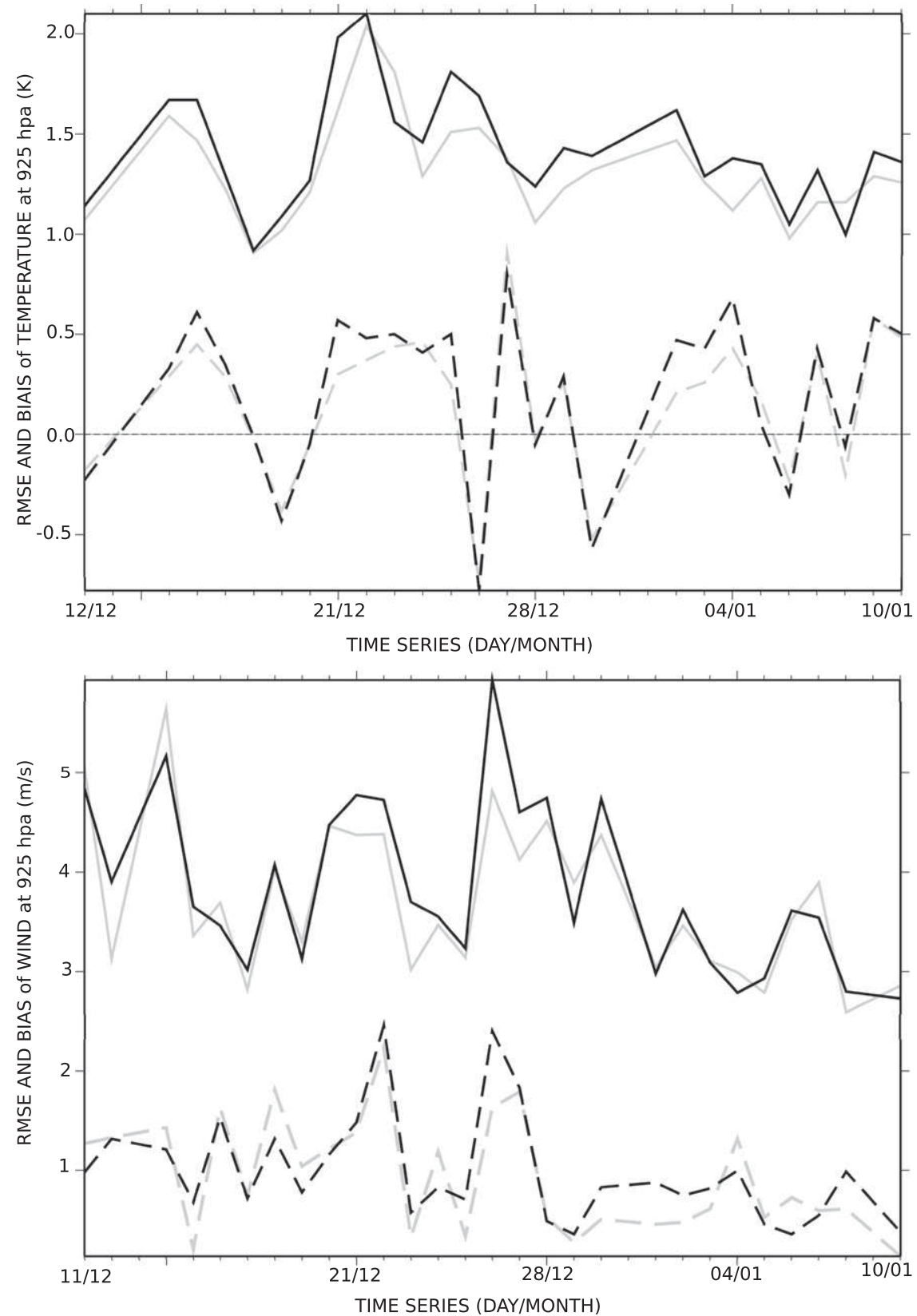

FIG. 10. Time series of RMS (solid lines) and bias (dashed lines) of the (top) 24-h forecast error in temperature at $925 \mathrm{hPa}$ (forecasts errors are calculated with respect to own analysis) and (bottom) 12-h forecast error in wind at $925 \mathrm{hPa}$ (forecasts errors are calculated with respect to radiosounding data), for REFLEC (gray lines) and NOREFLEC (dark lines), experiments between 12 Dec 2008 and 10 Jan 2009.

radar composite, was absolutely lacking and not forecasted in NOREFLEC. This better forecast leads to much more accurate 6-h accumulated precipitation forecasts in accordance with the accumulated rainfall measured by rain gauges (not shown). Associated to this convection, some high ground gusts have been observed between 80 and $90 \mathrm{~km} \mathrm{~h}^{-1}$. Figure 15 shows that for experiment REFLEC such wind gusts are forecasted at 0000 UTC 6 August 2009.

\section{Conclusions and discussion}

The implementation of radar reflectivity assimilation in the operational AROME 3D-Var system has been 

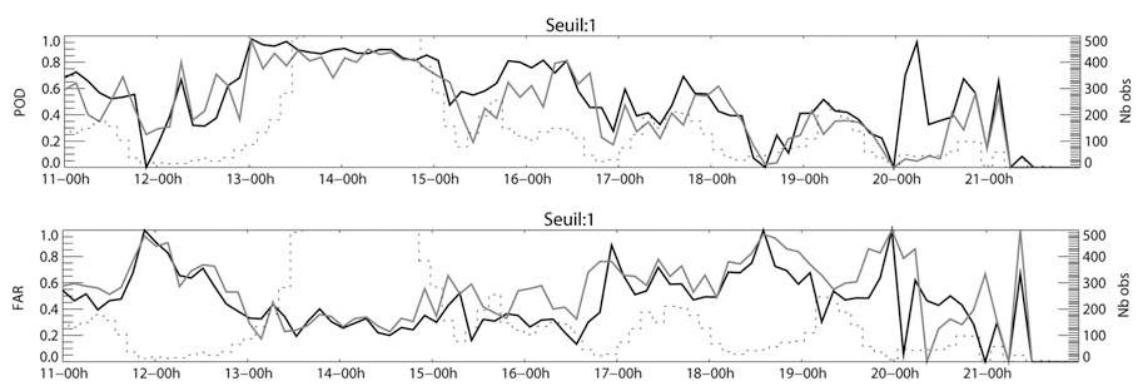

FIG. 11. Time series of POD and FAR values for 3-h forecast of accumulated precipitation for REFLEC (black line) and NOREFLEC (gray line) for the threshold $1 \mathrm{~mm} \mathrm{~h}^{-1}$. Probabilistic scores are computed against rain gauge measurements over the AROME France domain at 0000 UTC 11 Dec 2008 and at 0000 UTC 22 Dec 2008.

described. It follows feasibility studies performed by Caumont et al. (2010) with a number of new features in order to improve the assimilation technique, in particular to make it more efficient and more robust for operational purposes. This work required assumptions on the observation operator in particular to be compatible with the parallel code environment of AROME. Different preprocessing of the raw data have been required and introduced for the selection operationally. The systematic use of the "nonprecipitating" signal has been carried out, in particular to avoid systematic positive analysis biases due to the fact that the adopted methodology based on a 1D Bayesian inversion is able to create pseudo-observations whatever the model state (rainy or nonrainy).

A number of additional quality checks (QC) based on the $1 \mathrm{D}$ retrieval results have been introduced. One of these QCs is based on the ability of the model to create or remove rainy clouds as observed, even if the behavior of the implemented 1D inversion already shows a good behavior in most cases. However, the positive correlation between the relative humidity observation minus guess departures and the equivalent reflectivity departures is not very high. This result was expected but because of the use of climatological background-error covariances, pseudo-observations that do not verify a strong physical consistency (same sign between high relative humidity increments and reflectivity departures) have not been introduced in the 3D-Var.

Several observing system experiments (OSEs) over long periods of time have been performed and have shown a good impact on analysis and forecast skill scores. The assimilation of radar reflectivity brings significant information to the analyzed humidity field. A good impact of the moistening or drying areas is found in accordance with the observed precipitating patterns. On objective conventional scores, a positive impact is visible in particular on wind and temperature fields in the low and midatmosphere up to $24 \mathrm{~h}$ by comparison to own analyses and up to $12 \mathrm{~h}$ by comparison to radiosondes. Sensitivity tests on the specification and use of the minimum detectable values of reflectivity have been performed. The potential link between the relative humidity from the pseudo-observation and from the background has been studied, in particular through OREFLEC experiment. Only a very slight overdrying of the model has been found (not shown). Indeed the mean value of the observation minus background departures has been found slightly negative (with small positive humidity departures after analysis).

The assimilation of radar reflectivity became operational at Météo-France in the AROME model on 6 April 2010. Significant improvements to the precipitation probabilistic scores (up to the 6-h forecast range) have been found after the introduction of reflectivity data in the AROME system (not shown). On 24 November 2010 , the improved use of the "nonprecipitating" signal has been also introduced.

All these positive results validate the concept of using a two-step methodology to operationally assimilate radar reflectivities. However, the observation error statistics were estimated a priori at the beginning of the assimilation processing (the "true state" of the atmosphere is a priori not known). Work is currently under way to improve the specification of observation error covariances. Different algorithms have been proposed to estimate a posteriori observation error statistics (variances and spatial correlations) by Hollingsworth and Lönnberg (1986), Desroziers et al. (2005), and Fisher (2003). Such computations will improve the specification of observation errors and help to optimize the density of the observations to be assimilated. First results show a realistic specified standard deviation of the observation error, but the increase in observation density will probably require the introduction of observation error correlations. 


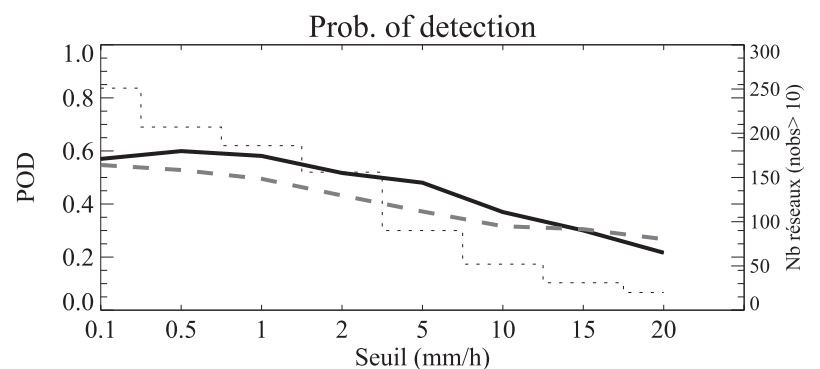

False Alarm Rate

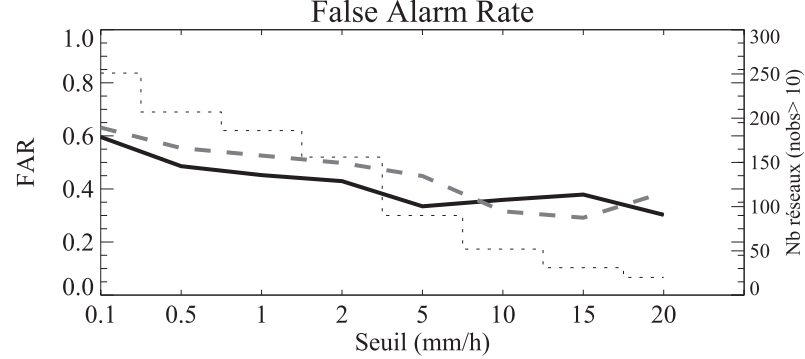

Equitable Threat Score

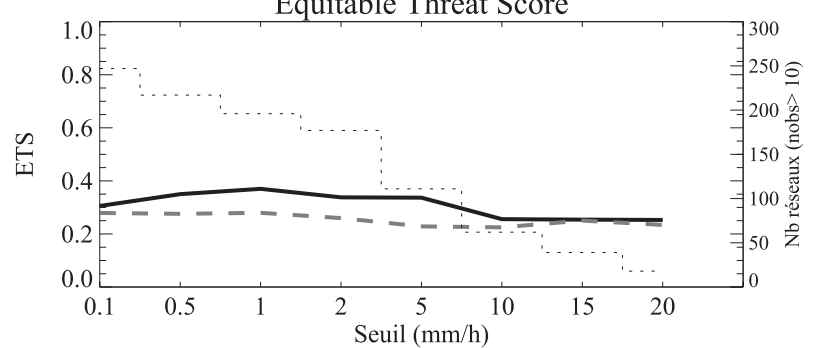

Frequency Bias

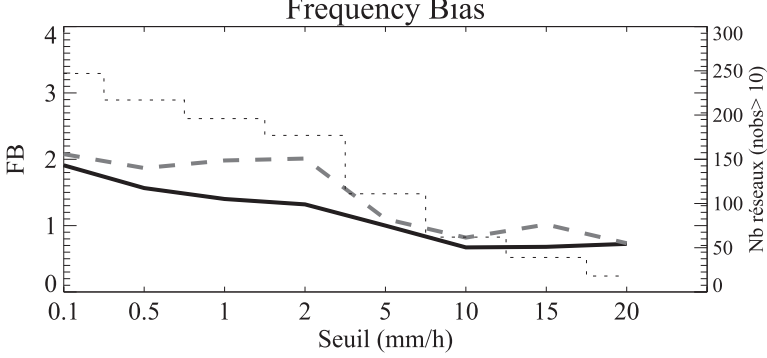

FIG. 12. Average of time series of 3-h cumulated precipitation scores vs rain gauge measurements for different thresholds between 0000 UTC 11 Dec 2008 and 1200 UTC 1 Jan 2009 for REFLEC (black line) and NOREFLEC (dashed line). (from top to bottom) Probability of detection, false alarm ratio, equitable threat score, and frequency bias. The dashed histogram indicates the number of forecasts taken into account in the score computation.

Concerning the modeling of forecast errors, the current climatological B matrix needs to be improved. Indeed, a significant day-to-day variability of these covariances that are linked to meteorological conditions over France has been found (Brousseau et al. 2012). Recent tests of using specific background-error covariances in precipitating areas have been carried out by Montmerle (2012). The results are promising on the dynamics of convective systems, although strongly dependent upon the

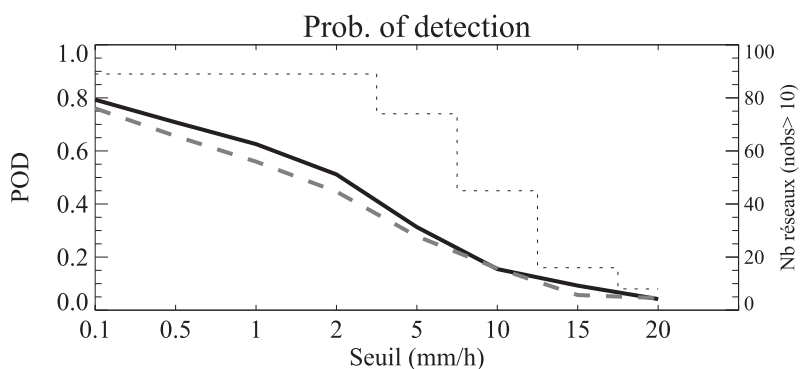

False Alarm Rate

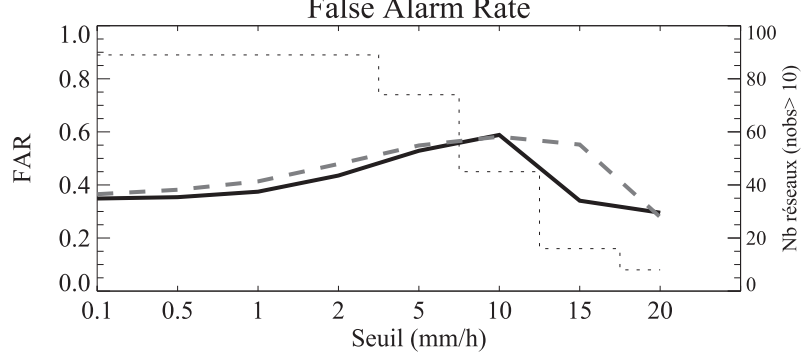

Equitable Threat Score

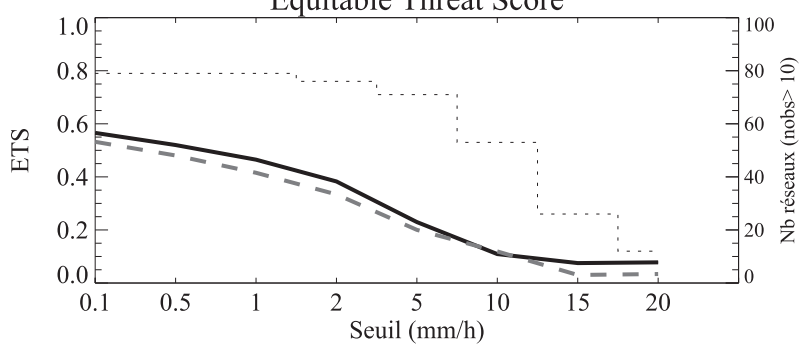

Frequency Bias

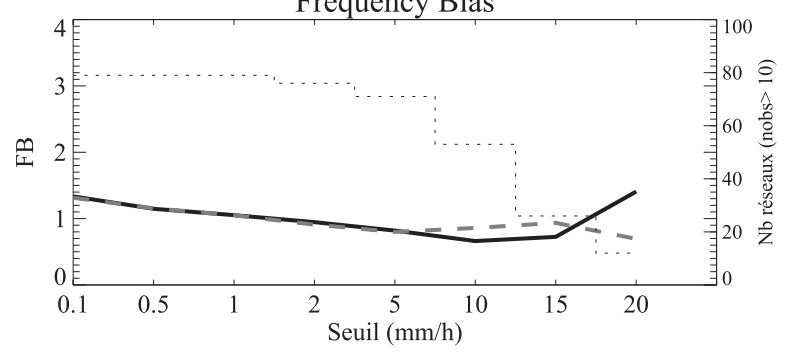

FIG. 13. Average of time series of 3-h cumulated precipitation scores vs rain gauge measurements for different thresholds between 0000 UTC 30 Apr and 0000 UTC 11 May 2010 for OREFLEC (black line) and OREFLECNOTUN (green dashed line). (from top to bottom) Probability of detection, false alarm ratio, equitable threat score, and frequency bias. The dashed histogram indicates the number of forecasts taken into account in the score computation.

precipitating systems sampled by the ensemble used to estimate error covariances. The extension of the control variable to hydrometeors and the possible direct assimilation of quantities provided by polarimetric radars need to be considered in the future. Michel et al. (2011) have estimated the covariance errors for hydrometeors, which is a first step in that direction.

Additional work, mainly performed in the Hydrological cycle in the Mediterranean Experiment (HyMex) 

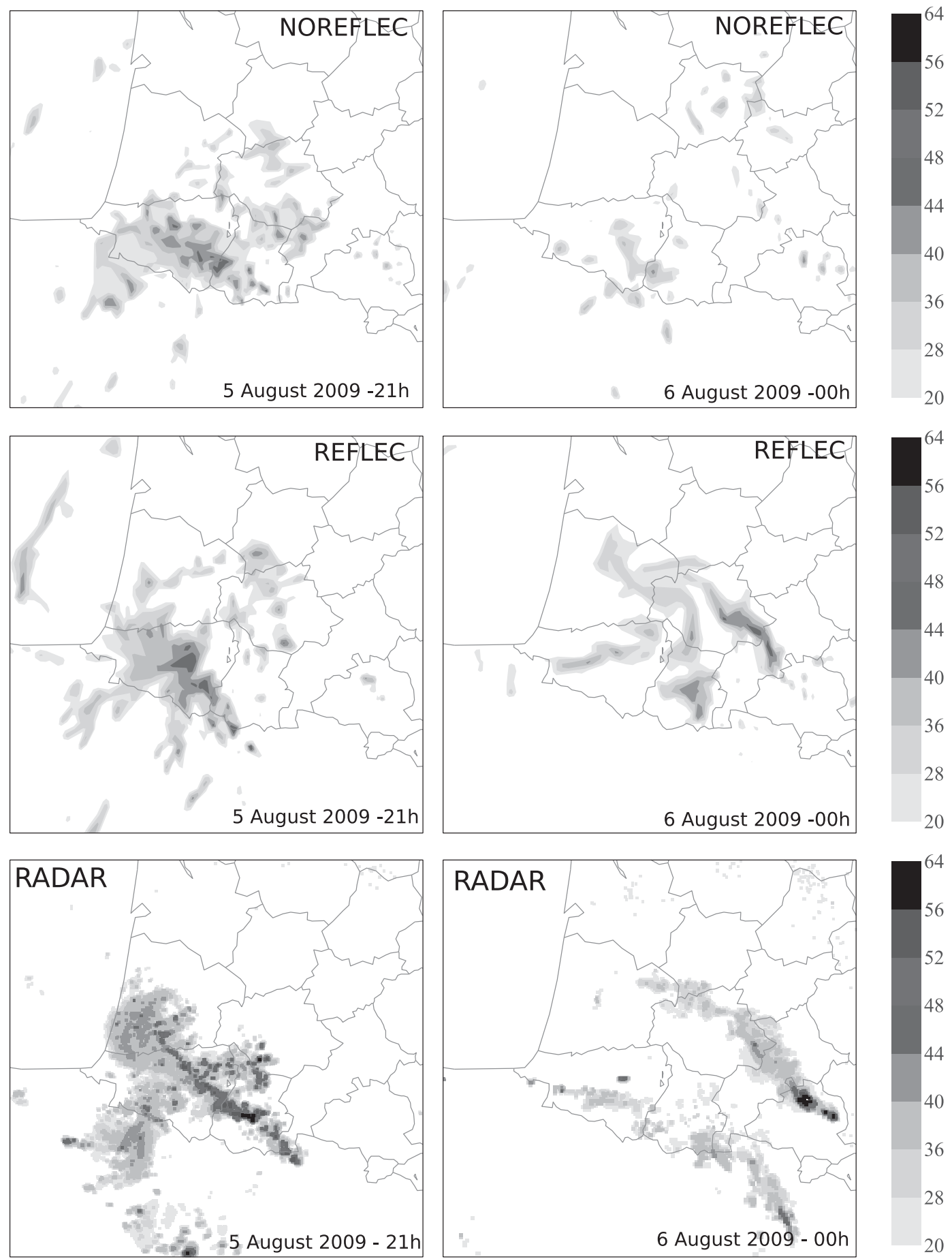

FIG. 14. Comparison between (middle) REFLEC and (top) NOREFLEC of the model reflectivity field at $2000 \mathrm{~m}$ MSL, and from the 3-h forecast on the (top and middle left) 2100 UTC 5 Aug 2009 and (top and middle right) 0000 UTC 6 Aug to the (bottom) radar composite.

framework (for a better quantification of the hydrological cycle in the Mediterranean) concerns the assimilation of data from X-band radars and radars from neighboring countries in the AROME 3D-Var system. Indeed, to improve the radar coverage in the southeast of France, Météo-France, in partnership with other French research institutes and administrations, is deploying a network of several dual-polarization X-band weather radars. This 

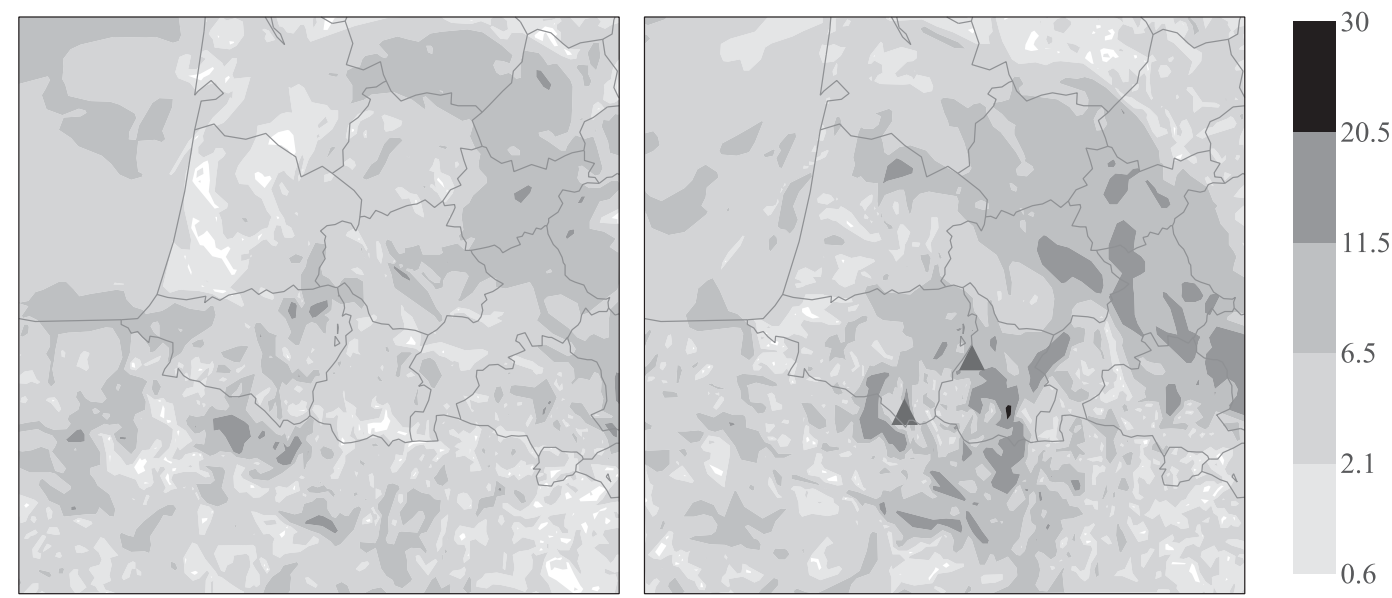

FIG. 15. Comparison between the 3-h forecasts of surface wind gusts $\left(\mathrm{m} \mathrm{s}^{-1}\right)$ between (left) NOREFLEC and (right) REFLEC at 0000 UTC 6 Aug 2009 with observed gusts (dark gray triangles) at Urdos (Pyrénées Atlantiques, $25.1 \mathrm{~m} \mathrm{~s}^{-1}$ ) and Ossun (Hautes-Pyrénées, $22.2 \mathrm{~m} \mathrm{~s}^{-1}$ ).

latter work is also used to evaluate the usefulness of additional information provided by polarimetric variables and associated algorithms in the assimilation AROME system. Activities on foreign radars will allow us to prepare data from European radars in the framework of European Meteorological Network's (EUMETNET's) Operational Programme for the Exchange of Weather Radar Information (OPERA) program. The methodology for using the "nonprecipitating" signal will be chosen according to the information available on radar technological features.

Acknowledgments. The authors are grateful to the anonymous reviewers who gave valuable suggestions. We are also very thankful to Jean-Antoine Maziejewski for his help in revising the manuscript. We wish to thank Marian Jurasek (Slovak Hydrometeorological Institute) and Günther Haase (Swedish Meteorological and HydroIogical Institute) for the fruitful cooperation in the early stages of this work. Thanks also go to François Bouttier and Véronique Ducrocq for the useful discussions of this work in its initial stage. Data have been kindly provided by the "Centre de Météorologie Radar" of Météo-France and the authors wish to thank in particular Laurent Perier for the careful preparation of the radar data for the assimilation.

\section{APPENDIX}

\section{Precipitation Scores}

Precipitation scores shown in this paper are defined hereafter; $G$ is the number of good forecasts (well forecasted and observed hit above the considered threshold), $F$ is the number of forecast hits but not observed, and $M$ is the number of misses (not forecasted but observed).

The probability of detection (POD) gives the fraction of good forecast events among all observed cases:

$$
\mathrm{POD}=\frac{G}{G+M} .
$$

The false alarm ratio (FAR) gives the fraction of forecast events that are observed to be nonevents:

$$
\mathrm{FAR}=\frac{F}{G+F} .
$$

The equitable threat score (ETS) is a skill score and defined as

$$
\mathrm{ETS}=\frac{G-G_{e}}{G+M+F-G_{e}},
$$

where $G_{e}$ is the number of good hits due to random chance, computed as (with $N$ the sample size)

$$
G_{e}=\frac{(G+F)(G+M)}{N} .
$$

The frequency bias (FB) measures the tendency to overor underestimate a rain rate and computed as

$$
\mathrm{FB}=\frac{G+F}{G+M} .
$$




\section{REFERENCES}

Aksoy, A., D. Dowell, and C. Snyder, 2009: A multicase comparative assessment of the ensemble Kalman filter for assimilation of radar observations. Part I: Storm-scale analyses. Mon. Wea. Rev., 137, 1805-1824, doi:10.1175/2008MWR2691.1.

,-- , and 2010: A multicase comparative assessment of the ensemble Kalman filter for assimilation of radar observations. Part II: Short-range ensemble forecasts. Mon. Wea. Rev., 138, 1273-1292, doi:10.1175/2009MWR3086.1.

Amerault, C., X. Zou, and J. Doyle, 2008: Tests of an adjoint mesoscale model with explicit moist physics on the cloud scale. Mon. Wea. Rev., 136, 2120-2132, doi:10.1175/2007MWR2259.1.

Bauer, P., A. J. Geer, P. Lopez, and D. Salmond, 2010: Direct 4D-Var assimilation of all-sky radiances. Part I: Implementation. Quart. J. Roy. Meteor. Soc., 136 (652), 1868-1885, doi:10.1002/qj.659.

— similation at operational NWP centres. Quart. J. Roy. Meteor. Soc., 137 (661), 1934-1951, doi:10.1002/qj.905.

Bech, J., U. Gjertsen, and G. Haase, 2007: Modelling weather radar beam propagation and topographical blockage at northern high latitudes. Quart. J. Roy. Meteor. Soc., 133 (626), 1191-1204, doi:10.1002/qj.98.

Bénard, P., J. Vivoda, J. Mašek, P. Smolíková, K. Yessad, C. Smith, R. Brožková, and J. Geleyn, 2010: Dynamical kernel of the Aladin-NH spectral limited-area model: Revised formulation and sensitivity experiments. Quart. J. Roy. Meteor. Soc., 136 (646), 155-169, doi:10.1002/qj.522.

Berre, L., 2000: Estimation of synoptic and mesoscale forecast error covariances in a limited-area model. Mon. Wea. Rev., 128, 644-667, doi:10.1175/1520-0493(2000)128<0644: EOSAMF $>2.0 . \mathrm{CO} ; 2$.

Brousseau, P., L. Berre, F. Bouttier, and G. Desroziers, 2011: Background-error covariances for a convective-scale dataassimilation system: AROME-France 3D-Var. Quart. J. Roy. Meteor. Soc., 137 (655), 409-422, doi:10.1002/qj.750.

$-, \ldots, \ldots$, and —_, 2012: Flow-dependent backgrounderror covariances for a convective-scale data assimilation system. Quart. J. Roy. Meteor. Soc., 138 (663), 310-322, doi:10.1002/qj.920.

— - G. Desroziers, F. Bouttier, and B. Chapnik, 2013: A posteriori diagnosis of the impact of observations on the AROMEFrance convective-scale data-assimilation system. Quart. J. Roy. Meteor. Soc., doi:10.1002/qj.2179, in press.

Caniaux, G., J. Redelsperger, and J. Lafore, 1994: A numerical study of the stratiform region of a fast-moving squall line. Part I: General description and water and heat budgets. J. Atmos. Sci., 51, 2046-2074, doi:10.1175/1520-0469(1994)051<2046: ANSOTS $>2.0 . \mathrm{CO} ; 2$.

Caumont, O., and Coauthors, 2006: A radar simulator for highresolution nonhydrostatic models. J. Atmos. Oceanic Technol., 23, 1049-1067, doi:10.1175/JTECH1905.1.

—, V. Ducrocq, É. Wattrelot, G. Jaubert, and S. PradierVabre, 2010: 1D+3DVar assimilation of radar reflectivity data: A proof of concept. Tellus, 62A, 173-187, doi:10.1111/ j.1600-0870.2009.00430.x

Caya, A., J. Sun, and C. Snyder, 2005: A comparison between the 4DVAR and the ensemble Kalman filter techniques for radar data assimilation. Mon. Wea. Rev., 133,3081-3094, doi:10.1175/ MWR3021.1.

Courtier, P., C. Freydier, J.-F. Geleyn, F. Rabier, and M. Rochas, 1991: The Arpege project at Météo-France. Proc. 1991 ECMWF
Seminar on Numerical Methods in Atmospheric Models, Shinfield Park, Reading, ECMWF, 193-231.

— J.-N. Thépaut, and A. Hollingsworth, 1994: A strategy for operational implementation of 4D-Var, using an incremental approach. Quart. J. Roy. Meteor. Soc., 120 (519), 1367-1387, doi:10.1002/qj.49712051912.

Desroziers, G., L. Berre, B. Chapnik, and P. Poli, 2005: Diagnosis of observation, background and analysis-error statistics in observation space. Quart. J. Roy. Meteor. Soc., 131 (613), 33853396, doi:10.1256/qj.05.108.

Doviak, R. J., and D. S. Zrnic, 1984: Doppler Radar and Weather Observations. Academic Press, 458 pp.

Dowell, D., F. Zhang, L. Wicker, C. Snyder, and N. Crook, 2004: Wind and temperature retrievals in the 17 May $1981 \mathrm{Ar}$ cadia, Oklahoma, supercell: Ensemble Kalman filter experiments. Mon. Wea. Rev., 132, 1982-2005, doi:10.1175/ 1520-0493(2004)132<1982:WATRIT>2.0.CO;2.

Ducrocq, V., D. Ricard, J.-P. Lafore, and F. Orain, 2002: Stormscale numerical rainfall prediction for five precipitating events over France: On the importance of the initial humidity field. Wea. Forecasting, 17, 1236-1256, doi:10.1175/ 1520-0434(2002)017<1236:SSNRPF > 2.0.CO;2.

Errico, R., P. Bauer, and J. Mahfouf, 2007: Issues regarding the assimilation of cloud and precipitation data. J. Atmos. Sci., 64, 3785-3798, doi:10.1175/2006JAS2044.1.

Fabry, F., 2010: For how long should what data be assimilated for the mesoscale forecasting of convection and why? Part II: On the observation signal from different sensors. Mon. Wea. Rev., 138, 256-264, doi:10.1175/2009MWR2884.1.

_ , and J. Sun, 2010: For how long should what data be assimilated for the mesoscale forecasting of convection and why? Part I: On the propagation of initial condition errors and their implications for data assimilation. Mon. Wea. Rev., 138, 242255, doi:10.1175/2009MWR2883.1.

Fischer, C., T. Montmerle, L. Berre, L. Auger, and S. E. Ştefănescu, 2005: An overview of the variational assimilation in the ALADIN/France numerical weather-prediction system. Quart. J. Roy. Meteor. Soc., 131 (613), 3477-3492, doi:10.1256/qj.05.115.

Fisher, M., 2003: Background error covariance modelling. Proc. ECMWF Seminar on Recent Developments in Data Assimilation from Atmosphere and Ocean, Reading, United Kingdom, ECMWF, 45-64.

Geer, A. J., P. Bauer, and P. Lopez, 2010: Direct 4D-Var assimilation of all-sky radiances. Part II: Assessment. Quart. J. Roy. Meteor. Soc., 136 (652), 1886-1905, doi:10.1002/qj.681.

Haase, G., J. Bech, E. Wattrelot, U. Gjertsen, and M. Jurasek, 2007: Towards the assimilation of radar reflectivities: Improving the observation operator by applying beam blockage information. Preprints, 32nd Conf. on Radar Meteorology, Cairns, Australia, Amer. Meteor. Soc., P4.2. [Available online at https://ams.confex.com/ams/33Radar/webprogram/ Paper123041.html.]

Hitschfeld, W., and J. Bordan, 1954: Errors inherent in the radar measurement of rainfall at attenuating wavelengths. J. Meteor., 11, 58-67, doi:10.1175/1520-0469(1954)011<0058: EIITRM $>2.0 . \mathrm{CO} ; 2$.

Hollingsworth, A., and P. Lönnberg, 1986: The statistical structure of short-range forecast errors as determined from radiosonde data. Part I: The wind field. Tellus, 38A, 111-136, doi:10.1111/ j.1600-0870.1986.tb00460.x.

Kummerow, C., and Coauthors, 2001: The evolution of the Goddard Profiling Algorithm (GPROF) for rainfall estimation from 
passive microwave sensors. J. Appl. Meteor., 40, 1801-1820, doi:10.1175/1520-0450(2001)040<1801:TEOTGP >2.0.CO;2.

Lafore, J., and Coauthors, 1998: The Meso-NH atmospheric simulation system. Part I: Adiabatic formulation and control simulations. Ann. Geophys., 16, 90-109, doi:10.1007/s00585-997-0090-6.

Lopez, P., and P. Bauer, 2007: "1D+ 4DVAR" assimilation of NCEP stage-IV radar and gauge hourly precipitation data at ECMWF. Mon. Wea. Rev., 135, 2506-2524, doi:10.1175/MWR3409.1.

Marécal, V., and J. Mahfouf, 2000: Variational retrieval of temperature and humidity profiles from TRMM precipitation data. Mon. Wea. Rev., 128, 3853-3866, doi:10.1175/ 1520-0493(2001)129<3853:VROTAH >2.0.CO;2.

$\longrightarrow$, and - 2002: Four-dimensional variational assimilation of total column water vapor in rainy areas. Mon. Wea. Rev., 130, 43-58, doi:10.1175/1520-0493(2002)130<0043: FDVAOT $>2.0 . \mathrm{CO} ; 2$.

Michel, Y., T. Auligné, and T. Montmerle, 2011: Heterogeneous convective-scale background error covariances with the inclusion of hydrometeor variables. Mon. Wea. Rev., 139, 29943015, doi:10.1175/2011MWR3632.1.

Montmerle, T., 2012: Optimization of the assimilation of radar data at the convective scale using specific background error covariances in precipitation. Mon. Wea. Rev., 140, 3495-3506, doi:10.1175/MWR-D-12-00008.1.

_ and C. Faccani, 2009: Mesoscale assimilation of radial velocities from Doppler radars in a preoperational framework. Mon. Wea. Rev., 137, 1939-1953, doi:10.1175/2008MWR2725.1.

_ , and L. Berre, 2010: Diagnosis and formulation of heterogeneous background-error covariances at the mesoscale. Quart. J. Roy. Meteor. Soc., 136 (651), 1408-1420, doi:10.1002/qj.655.

Olson, W., C. Kummerow, Y. Hong, and W. Tao, 1999: Atmospheric latent heating distributions in the tropics derived from satellite passive microwave radiometer measurements. J. Appl. Meteor., 38, 633-664, doi:10.1175/1520-0450(1999)038<0633: ALHDIT>2.0.CO;2.

Park, S. K., and K. K. Droegemeier, 1997: Validity of the tangent linear approximation in a moist convective cloud model. Mon. Wea. Rev., 125, 3320-3340, doi:10.1175/1520-0493(1997)125<3320: VOTTLA $>2.0 . \mathrm{CO} ; 2$

Pinty, J., and P. Jabouille, 1998: A mixed-phase cloud parameterization for use in a mesoscale non-hydrostatic model: Simulations of a squall line and of orographic precipitations. Preprints, Conf. on Cloud Physics, Everett, WA, Amer. Meteor. Soc. 217-220.

Probert-Jones, J., 1962: The radar equation in meteorology. Quart. J. Roy. Meteor. Soc., 88 (378), 485-495, doi:10.1002/ qj. 49708837810 .

Sauvageot, H., and J. Coulomb, 1982: Radarmétéorologie: Télédétection Active de l'Atmosphère (Radar Meteorology: Active Remote Sensing of the Atmosphere). Eyrolles, 296 pp.

Seity, Y., P. Brousseau, S. Malardel, G. Hello, P. Bénard, F. Bouttier, C. Lac, and V. Masson, 2011: The AROME-France convective-scale operational model. Mon. Wea. Rev., 139, 976991, doi:10.1175/2010MWR3425.1.

Snyder, C., and F. Zhang, 2003: Assimilation of simulated Doppler radar observations with an ensemble Kalman filter. Mon. Wea. Rev., 131, 1663-1677, doi:10.1175//2555.1.

Sun, J., and N. Crook, 1997: Dynamical and microphysical retrieval from Doppler radar observations using a cloud model and its adjoint. Part I: Model development and simulated data experiments. J. Atmos. Sci., 54, 1642-1661, doi:10.1175/ 1520-0469(1997)054<1642:DAMRFD>2.0.CO;2.

- and H. Wang, 2013: Radar data assimilation with WRF 4D-Var. Part II: Comparison with 3D-Var for a squall line over the U.S. Great Plains. Mon. Wea. Rev., 141, 2245-2264, doi:10.1175/MWR-D-12-00169.1.

Tabary, P., 2007: The new French operational radar rainfall product. Part I: Methodology. Wea. Forecasting, 22, 393-408, doi:10.1175/WAF1004.1.

, J. Desplats, K. Do Khac, F. Eideliman, C. Gueguen, and J. Heinrich, 2007: The new French operational radar rainfall product. Part II: Validation. Wea. Forecasting, 22, 409-427, doi:10.1175/WAF1005.1.

Tong, M., and M. Xue, 2005: Ensemble Kalman filter assimilation of Doppler radar data with a compressible nonhydrostatic model: OSS experiments. Mon. Wea. Rev., 133, 1789-1807, doi:10.1175/MWR2898.1.

Wang, H., T. Auligné, and H. Morrison, 2012: Impact of microphysics scheme complexity on the propagation of initial perturbations. Mon. Wea. Rev., 140, 2287-2296, doi:10.1175/ MWR-D-12-00005.1.

—, J. Sun, S. Fan, and X.-Y. Huang, 2013a: Indirect assimilation of radar reflectivity with WRF 3D-Var and its impact on prediction of four summertime convective events. J. Appl. Meteor. Climatol., 52, 889-902, doi:10.1175/ JAMC-D-12-0120.1.

,-- X. Zhang, X.-Y. Huang, and T. Auligné, 2013b: Radar data assimilation with WRF 4D-Var. Part I: System development and preliminary testing. Mon. Wea. Rev., 141, 2224-2244, doi:10.1175/MWR-D-12-00168.1.

Wattrelot, E., 2009: Implementation of the 1D+3DVar assimilation of radar reflectivities in the AROME model at MétéoFrance. Joint 19th ALADIN Workshop \& HIRLAM ASM 2009, Utrecht, Netherlands, ALADIN Consortium. [Available online at http://www.cnrm.meteo.fr/aladin/spip.php?article118\& lang $=$ en/TU-EW.pdf.]

, O. Caumont, S. Pradier-Vabre, M. Jurasek, and G. Haase, 2008: 1D+3DVar assimilation of radar reflectivities in the pre-operational AROME model at Météo-France. Proc. Fifth Conf. on Radar in Meteorology and Hydrology, Helsinki, Finland, Finnish Meteorological Institute, 6 pp. [Available online at http://erad2008.fmi.fi/proceedings/extended/erad20080097-extended.pdf.]

Wu, B., J. Verlinde, and J. Sun, 2000: Dynamical and microphysical retrievals from Doppler radar observations of a deep convective cloud. J. Atmos. Sci., 57, 262-283, doi:10.1175/ 1520-0469(2000)057<0262:DAMRFD >2.0.CO;2.

Xiao, Q., Y. Kuo, J. Sun, W. Lee, D. Barker, and E. Lim, 2007: An approach of radar reflectivity data assimilation and its assessment with the inland QPF of Typhoon Rusa (2002) at landfall. J. Appl. Meteor. Climatol., 46, 14-22, doi:10.1175/ JAM2439.1.

Yan, X., V. Ducrocq, G. Jaubert, P. Brousseau, P. Poli, C. Champollion, C. Flamant, and K. Boniface, 2009: The benefit of GPS zenith delay assimilation to high-resolution quantitative precipitation forecasts: A case-study from COPS IOP 9. Quart. J. Roy. Meteor. Soc., 135 (644), 1788-1800, doi:10.1002/ qj.508. 